\title{
Aluminum Clad Spent Nuclear Fuel Long Term Dry Storage Technical Issues Action Plan - Technical and Engineering Activities
}

November 2017

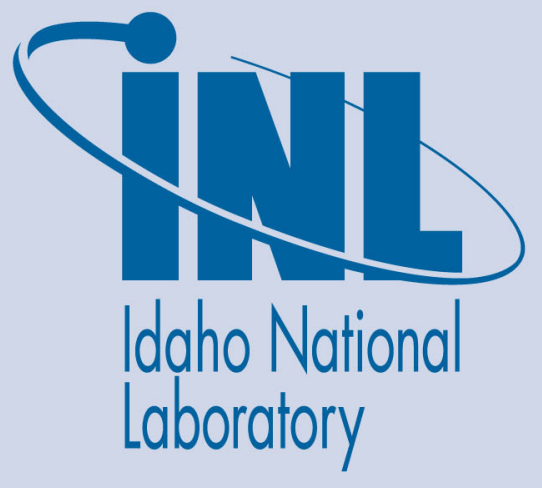

The INL is a U.S. Department of Energy National Laboratory operated by Battelle Energy Alliance 


\section{DISCLAIMER}

This information was prepared as an account of work sponsored by an agency of the U.S. Government. Neither the U.S. Government nor any agency thereof, nor any of their employees, makes any warranty, expressed or implied, or assumes any legal liability or responsibility for the accuracy, completeness, or usefulness, of any information, apparatus, product, or process disclosed, or represents that its use would not infringe privately owned rights. References herein to any specific commercial product, process, or service by trade name, trade mark, manufacturer, or otherwise, does not necessarily constitute or imply its endorsement, recommendation, or favoring by the U.S. Government or any agency thereof. The views and opinions of authors expressed herein do not necessarily state or reflect those of the U.S. Government or any agency thereof. 


\section{Aluminum Clad Spent Nuclear Fuel Long Term Dry Storage Technical Issues Action Plan - Technical and Engineering Activities}

November 2017

Idaho National Laboratory Idaho Falls, Idaho 83415

http://www.inl.gov

Prepared for the

U.S. Department of Energy

Office of Environmental Management

Under DOE Idaho Operations Office

Contract DE-AC07-05ID14517 


\section{Aluminum Clad Spent Nuclear Fuel Long Term Dry Storage Technical Issues Action Plan - Technical and Engineering Activities}

INL/EXT-17-43908

November 2017

Approved by:

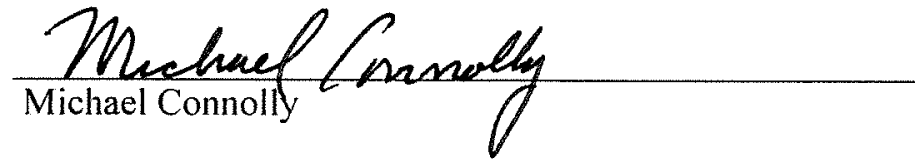

Nov 21, 2017 


\section{SUMMARY}

The DOE Spent Nuclear Fuel Working Group (SNFWG)'s report on technical considerations and challenges for extended dry storage of aluminum-clad spent nuclear fuel (ASNF) entitled, Aluminum-Clad Spent Nuclear Fuel: Technical Consideration and Challenges for Extended (>50 Years) Dry Storage, DOE/ID RPT-1575, June 2017 identified five knowledge gaps and technical data needs. This DOE SNFWG report also made several recommendations including one to develop an action plan to identify needed technical and engineering activities and analyses to address the identified knowledge gaps and technical data needs. A team composed of twenty SNF management experts and appropriate subject matter experts from the Idaho National Laboratory and Savannah River National Laboratory was assembled to develop this action plan. The action plan identifies and recommends six technical and engineering tasks and estimated cost and schedule for task completion. It is estimated that $\$ 5 \mathrm{M}$ and 18 months will be required to execute the recommended tasks. 


\section{CONTENTS}

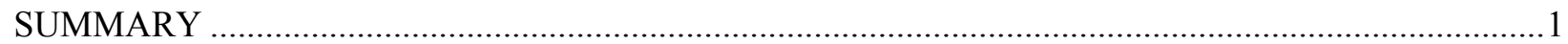

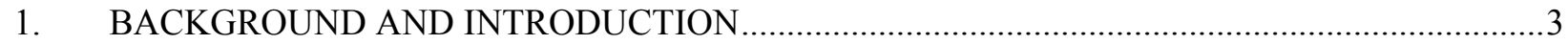

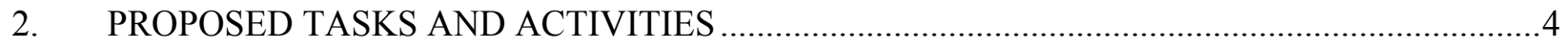

2.1 Task 1: Oxyhydroxide Layer Behavior and Chemistry .....................................................

2.2 Task 2: Oxide Layer Radiolytic Gas Generation Resolution ............................................5

2.2 Task 3: Sealed and Vented Episodic Breathing and Gas Generation Prediction .....................5

2.4 Task 4: Performance of ASNF in Dry Storage ...................................................................6

2.5 Task 5: Oxide Layer Response to Drying...................................................................

2.6 Task 6: Surrogate Sample Preparation and Validation .......................................................

2.7 Task Interfaces and Coordination/Integration ............................................................

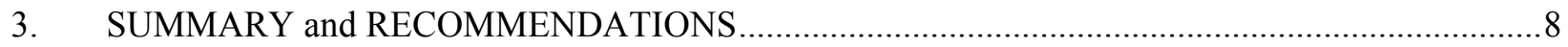

Appendix A INL-SRNL Aluminum Spent Nuclear Fuel Dry Storage Technical Issues Meeting, October $10,2017$. 10

\section{FIGURES}

Figure 1. Diagram of ASNF concerns for different storage configurations .......................................... 3

Figure 2. ASNF assembly after irradiation and storage in poor quality water illustrating the oxide layers

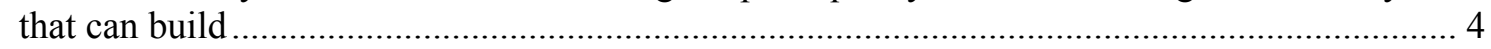

Figure 3. Corrosion site near the oxide layer in aluminum 6061 ...................................................... 5

Figure 4. Proposed multiscale, multiphysics modeling approach to accurately predict system behavior as a result of episodic breathing and radiolytic gas generation ....................................................... 6

Figure 5. Examples of potential candidates for visual and material inspection ...................................... 7

Figure 6. Illustration of information exchange between tasks............................................................... 8

\section{TABLES}

Table 1. Recommended task funding assuming FY17 and FY18 funds availability 9 


\section{Aluminum Clad Spent Nuclear Fuel Long Term Dry Storage Technical Issues Action Plan - Technical and Engineering Activities}

\section{BACKGROUND AND INTRODUCTION}

This report (hereafter referred to as "the action plan") describes potential technical, engineering, modeling activities and analyses that address previously-identified knowledge gaps and technical data needs presented in the DOE Spent Nuclear Fuel Working Group (SNFWG)'s report on technical considerations and challenges for extended dry storage of aluminum-clad spent nuclear fuel (ASNF) entitled, Aluminum-Clad Spent Nuclear Fuel: Technical Consideration and Challenges for Extended (>50 Years) Dry Storage, DOE/ID RPT-1575, June 2017. This action plan addresses the SNFWG report recommendation to develop an action plan. The SNFWG report identified five data/knowledge gaps that need to be addressed to help inform decision-makers on the environmental, safety, and long-term programmatic risks associated with a management strategy for aluminumclad SNF in extended (i.e., greater than 50 years) dry storage. These knowledge gaps and technical data needs are:

1. Behavior/chemistry of oxyhydroxide layers for the range of ASNF fuel designs and dry storage configurations

2. Resolution of radiolytic gas generation data for ASNF oxyhydroxide layers

3. Combined effect of episodic breathing and radiolytic generation of potentially corrosive gases in sealed and vented systems

4. Performance of research test reactor (RTR) ASNF in existing dry storage systems

5. Effects of high-temperature (i.e., greater than $100^{\circ} \mathrm{C}$ ) drying on the chemistry and behavior of oxyhydroxide layers.

Fundamentally, these knowledge gaps were identified as potential issues requiring evaluation to ensure safe and compliant extended dry storage of ASNF sealed and inert or vented dry storage configurations. Key safety criteria that must be met in any storage configuration are radiologic shielding, material confinement, subcriticality, and retrievability, which lead to specific concerns based on storage configuration as illustrated in Figure 1.

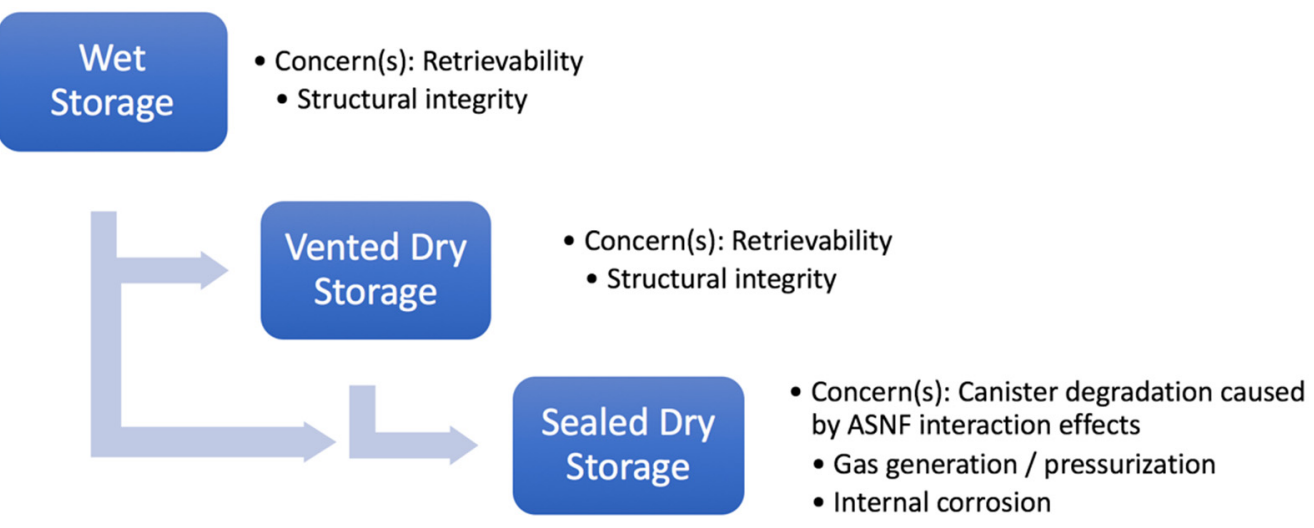

Figure 1. Diagram of ASNF concerns for different storage configurations 
DOE-ID/RPT-1575 report recommends taking several actions one of which is directed at addressing the knowledge gaps and technical data needs. Specifically it recommends developing an action plan to identify and execute needed technical and engineering activities that address identified knowledge gaps and technical data needs. This action plan is in direct response to this DOE recommended action. Because of the nature of the identified knowledge gaps and data needs a team of SNF management and respective subject experts was assembled to develop this action plan. The twenty person team was composed of subject matter experts from the Idaho National Laboratory (INL), Savannah River National Laboratory, and Fluor Idaho. Leads from each institution were identified for each of the five need areas and charged with developing a problem statement, research questions, proposed research scope, identification of interface needs with other identified need areas and expected research outcomes. Two of the primary assumptions the sub-teams worked to are; research activities need to be completed in 18 months from initiation, and $\$ 5 \mathrm{M}$ would be available to support the research activities. Activity to develop this action plan was initiated on Sept 4, 2017. A one-day group meeting was held at the INL on October 10, 2017 and all other sub-team interaction took place via teleconference and email exchanges. Appendix A contains materials generated in support of the October 10, 2017 meeting.

The improved understanding of ASNF behavior gained by performing the tasks proposed in this action plan is critical to defend safe, extended storage in current and future configurations as well as to provide information for future transportation, conditioning, and disposal of the fuel. This plan provides a high-level overview of each proposed task, how the tasks are interrelated, and recommends steps necessary to move forward with filling the identified knowledge gaps (i.e., actions to resolve needs).

\section{PROPOSED TASKS AND ACTIVITIES}

Each task is based on addressing the knowledge and data gaps identified in the SNFWG report on challenges with extended ASNF storage. As the identified knowledge gaps and technical data needs are interdependent, the proposed tasks are also interdependent.

\subsection{Task 1: Oxyhydroxide Layer Behavior and Chemistry}

The first step in understanding how ASNF will perform over extended storage periods is to understand the behavior of oxide/oxyhydroxide films that are created during in-reactor operations and out-of-reactor storage. This film formation is dependent on numerous conditions including temperatures, irradiation history, heat flux, and water quality (see Figure 2). This task will seek to answer several questions; are there mechanisms which could alter the aluminum oxide/oxyhydroxide layers during extended storage, and under what conditions do these layers decompose to release species that can lead to canister integrity issues? This task will characterize thicknesses and growth rates of oxide layers based on fuel history, characterize and test material properties for the oxides prevalent on ASNF, and assess both corrosion and radiolysis reactions in different oxide layers.

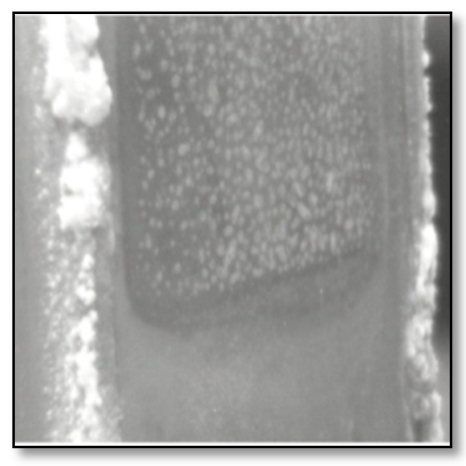

Figure 2. ASNF assembly after irradiation and storage in poor quality water illustrating the oxide layers that can build 
The identified sub-tasks to fill this knowledge gap are: (1) determine alloys and conditions of interest, (2) grow oxides on aluminum alloys, (3) determine oxide film reactions and gas generation, (4) measure the mechanical properties of different oxide films, and (5) examine the mechanisms for accelerated degradation of oxide films as function of varying environmental conditions. Thermodynamic and kinetic modeling will be performed to predict oxide layers as a function of temperature, $\mathrm{pH}$, and neutronics history. It is anticipated the results of this task will help: (1) predict gas generation due to corrosion and thermal decomposition, (2) understand behavior of oxide/oxyhydroxide layers under conditions representative of wet and dry storage, (3) provide defensible bounding thickness and growth rate of oxide layer, and (4) provide representative test materials.

\subsection{Task 2: Oxide Layer Radiolytic Gas Generation Resolution}

While Task 1 will provide information regarding the amount of gas generated due to thermal effects on or corrosion of oxide/oxyhydroxide layer, this task is focused on radiolysis of the oxide/oxyhydroxide layer and gaseous sources present within the storage canister. The resultant production of radiolytic gases may lead to canister degradation or integrity concerns. Task 2 will provide a comprehensive radiolysis "blueprint" of all system components (aluminum cladding, oxide layers, and stainless steel canisters, in-canister gaseous environment) to accurately represent in-canister conditions. Specifically, this task will answer the following questions: what important gases are produced inside sealed and vented ASNF canisters, what are the rates of radiolytic gas generation, what are the radiolytic degradation mechanisms, and can the in-canister conditions be predicted and forecasted based on these mechanisms (see Figure 3)?

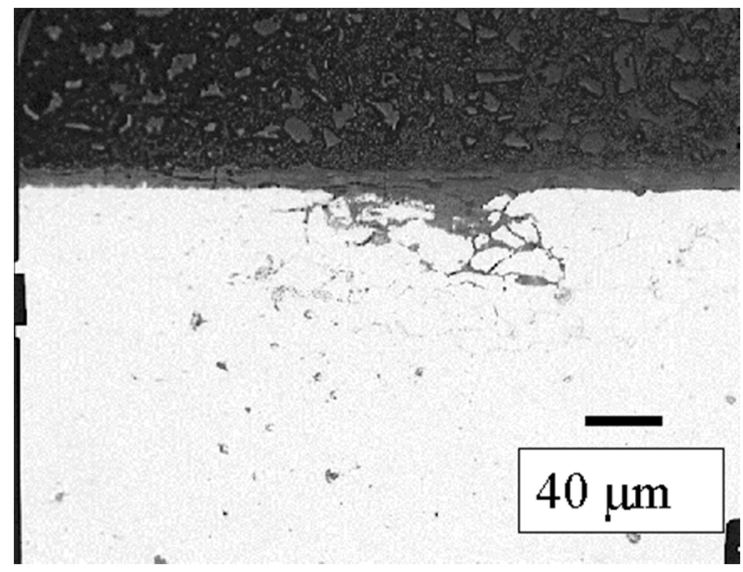

Figure 3. Corrosion site near the oxide layer in aluminum 6061

The identified sub-tasks to fill this knowledge gap are: (1) perform comprehensive literature review, (2) develop experimental test condition matrix based on temperature, in-canister atmosphere, and oxide thicknesses, (3) develop a reliable method for atmosphere control and measurement of gas phase composition changes, (4) perform gamma irradiation of samples and measure gas generation, (5) and develop predictive multi-scale kinetic tool to provide in-canister radiation chemistry.

\subsection{Task 3: Sealed and Vented System Episodic Breathing and Gas Generation Prediction}

Task 3 attempts to comprehensively model the combined effects of episodic breathing (in the vented canisters) with the radiolytic gas generation on the aluminum clad, oxide layers, canister, and other system components. Diffusional and convective exchanges of reactive gaseous species and heat inside the canister with ambient air induced by episodic breathing in vented, unsealed storage system will shift the chemical equilibrium conditions inside the canister and affect the amount of radiolytic production of corrosive gases. Development of a 
comprehensive understanding of the coupled effects of episodic breathing and long-term spatial-temporal evolution of radiolysis-generated corrosive gases inside the canister on the degradation pathways of all structural components (e.g., Al cladding, oxyhydroxide layers, and fuel bucket) is critical to accurately understand potential extended storage implications. This task will answer the following questions: what are the temperature fields inside and outside of the ASNF canisters at different times, what are the concentration fields of radiolysisgenerated corrosive gasses during extended storage, what are the water vapor concentration fields during extended storage, how do the structural materials and fuel elements age over extended storage?

\section{Fuel Scale Canister Scale}
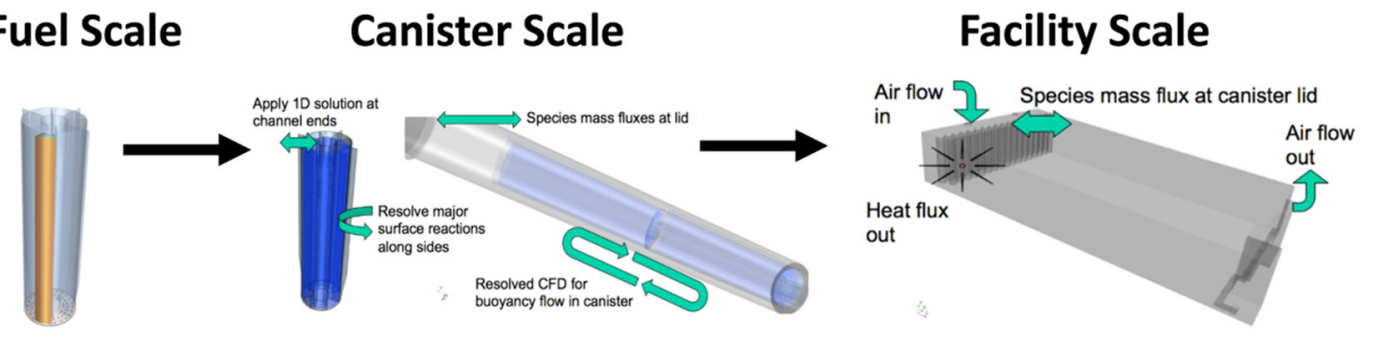

Figure 4. Proposed multiscale, multiphysics modeling approach to accurately predict system behavior as a result of episodic breathing and radiolytic gas generation

The identified sub-task to fill this knowledge gap are: (1) Determine appropriate storage system conditions, (2) develop gas phase models, (3) incorporate data from oxide layer experiments, (4) develop vented canister model, (5) demonstrate model's predictive capability.

This task is focused on the vented storage configuration currently utilized at the Idaho National Laboratory. However, the modeling approach and models (e.g. canister model) developed can subsequently be adopted to model sealed and inert storage configurations.

\subsection{Task 4: Performance of ASNF in Dry Storage}

Task 4 will physically inspect ASNF, with priority focus on ATR fuel, in dry storage to establish how the ASNF is performing over the storage lifetime. At a minimum visual inspection must be performed to validate concerns about expected corrosion and radiolytic phenomena and to assure that storage conditions have not introduced new, unexpected behavior. In addition to visual inspection, there are additional inspection options including: instrumenting a vented canister to measure humidity, temperature, and other characteristics of interest, scraping an oxide sample for chemical and phase analysis, and more-intensive non-destructive examination and destructive examination of the ASNF. ASNF has been identified at SRS that will be used for validating surrogate sample preparation will provide additional data for this task. Example ASNF plate fuel and dry storage systems are shown in 5. Collaboration with INL ATR programs on ATR fuel element post irradiation examination (PIE) is under discussion but pending decision. 

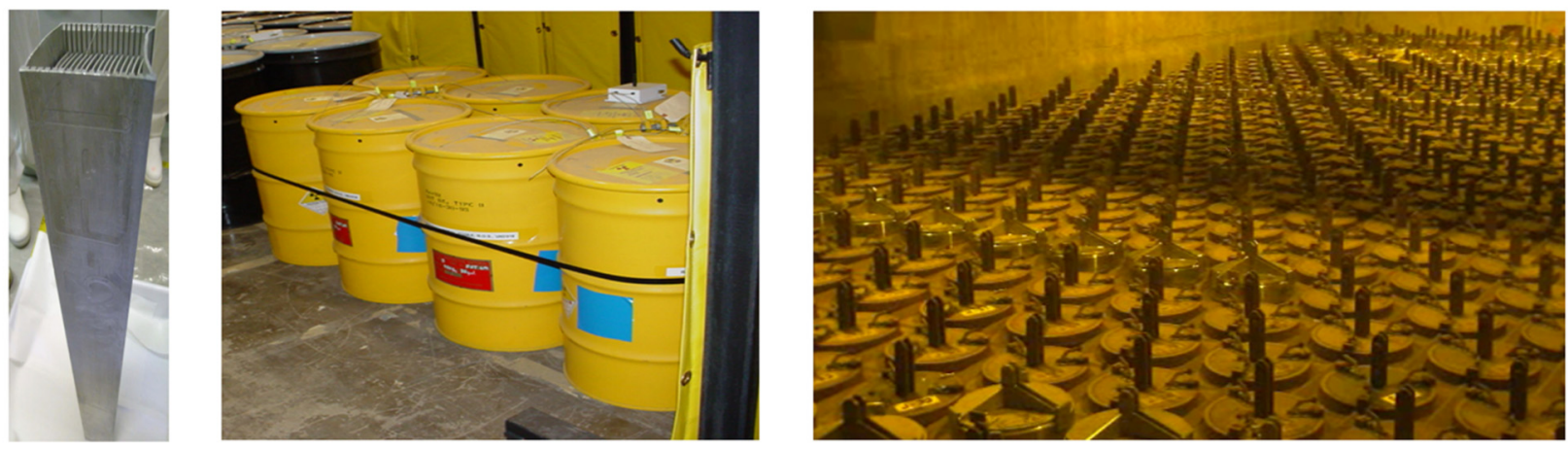

Figure 5. Examples of potential candidates for visual and material inspection

The identified potential sub-tasks to fill this knowledge gap are: (1) determine appropriate ASNF candidates available in dry storage, (2) develop (or confirm) a process to access and visually inspect selected ASNF, (3) visually inspect ASNF, (4) develop (or confirm) a process to "scrape" the oxide layers of the selected ASNF, and (5) analyze scraped sample for material characteristics and oxide phase composition.

\subsection{Task 5: Oxide Layer Response to Drying}

Task 5 will analyze the effects of drying ASNF on the development and composition of oxide layers. The underlying goal is to understand how effectively different drying procedures (e.g., temperature, vacuum, forced helium) remove the chemically bound water in some of the oxide layers as well as impact the formation/transformation of those layers. This task will analyze a wide range of oxide films and aluminum alloys to ensure a broad understanding base is developed.

The identified sub-tasks to fill this knowledge gap are: (1) identify or develop representative aluminum materials for testing, (2) evaluate small-scale dehydration of oxide films, (3) develop a mock-up of ASNF design(s) for a range of films and layered structures, and (4) test scaled-up drying using forced gas dehydration technology and/or throttled heated gas vacuum drying technology.

\subsection{Surrogate Sample Preparation and Validation}

Investigation of knowledge gaps and technical data needs will require use of laboratory grown surrogate materials. Validating that surrogate materials accurately represent ASNF oxyhydroxide layer composition (e.g., gibbsite, bayerite, and boehmite) is critical to ensure results of proposed investigations are representative of actual ASNF. The DOE inventory of ASNF is composed of different ASNF designs fabricated primarily from three different aluminum alloys $(1100,5052$, and 6061), with the predominant alloy type being 6061. Alloy type 6061 is used in fabricating fuel for the Advanced Test Reactor and the High Flux Irradiation Reactor. Under reactor conditions the cladding is exposed to an extreme environment: high temperatures, immersion in chemically treated moderators and coolants, and an intense multi-component radiation field (alpha particles, beta particles, gamma and X-rays, neutrons, and fission fragments), all ultimately leading to various forms of corrosion (e.g. pitting, crevice, galvanic, and intergranular). These in-reactor conditions coupled with varying water quality associated with out-of-reactor water storage influence fuel surface conditions and oxide/oxyhydroxide composition and growth. This combination of factors may result in varying oxide/oxyhydroxide layer composition depending upon ASNF fuel type, reactor history, and wet storage conditions. Because of this, development and validation of surrogate materials will be undertaken in sample preparation and validation task but these materials will be used in multiple tasks. This task will include characterization of oxide/oxyhydroxide layers on actual SRS SNF materials and preparation of representative surrogate materials for use in other tasks. 


\subsection{Task Interfaces and Coordination/Integration}

This list of tasks is expected to work together to answer the identified knowledge and data gaps. Figure 6 illustrates at a high-level the information exchanges that will take place between the different tasks. Tasks will be executed by a team composed of INL, SRNL, and Fluor Idaho staff at multiple facilities located at INL and SRNL. Additionally, as shown in Figure 6 data and information sharing across tasks will be required. Task coordination and integration will be required to ensure success.

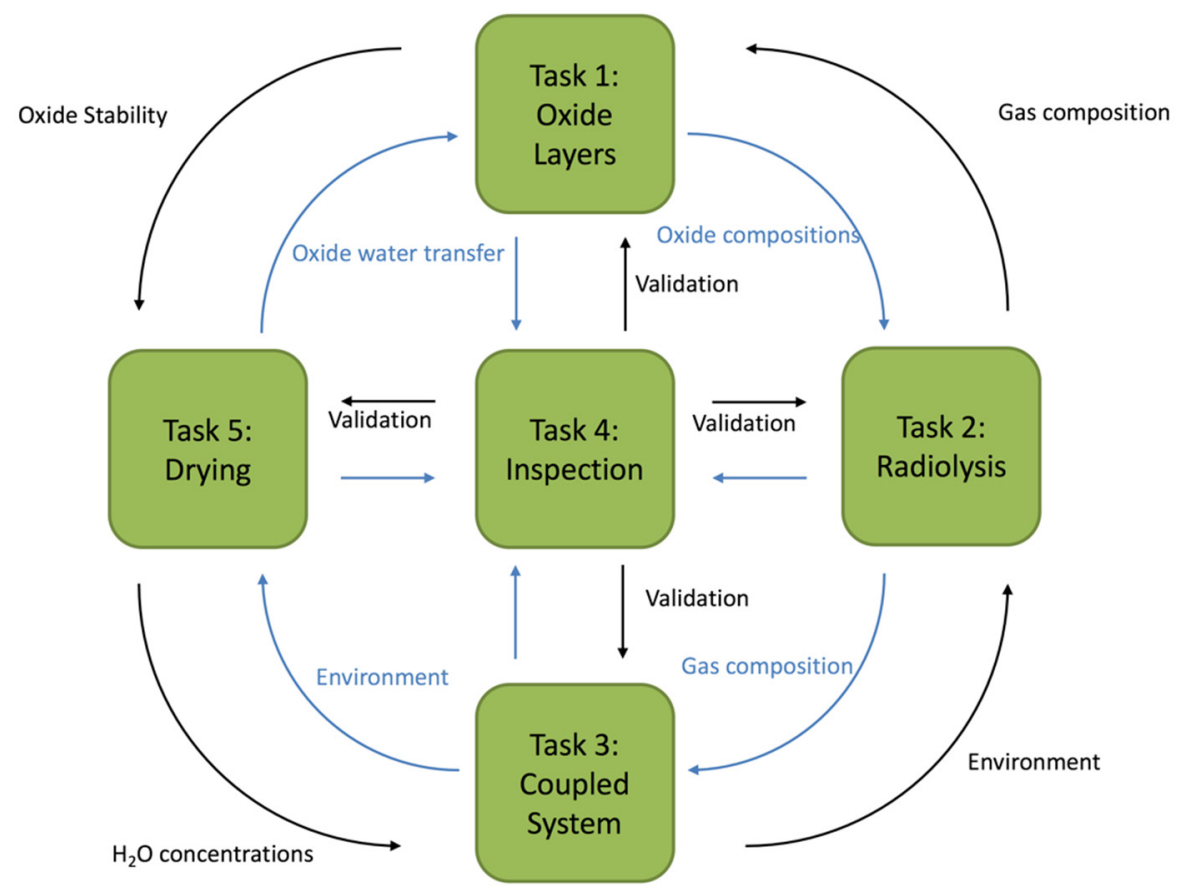

Figure 6. Illustration of information exchange between tasks

This diagram illustrates the interconnection between the different tasks as well as illustrates the importance of each task in the broader action plan.

\section{SUMMARY AND RECOMMENDATIONS}

The approach taken to develop an action plan in response to recommendations made in DOE-ID/RPT-1575 by developing a team of subject matter experts from INL, SRNL, and Fluor Idaho has resulted in identification of specific technical and engineering studies designed to address the five knowledge gaps and technical need areas identified in the DOE report. The recommended technical and engineering studies can be completed within 18 months for approximately $\$ 5 \mathrm{M}$. Table 1 provides a breakdown of the specific tasks and recommended funding levels for each task by fiscal year. Fiscal year 2017 carryover funds are available to initiate the tasks and it is recommended that execution begin in December 2017. It is intended that tasks 3, 4, 5, and sample preparation/validation will leverage, to extent possible, other DOE EM and NE projects and activities as appropriate. 
Table 1. Recommended task funding assuming FY17 and FY18 funds availability

\begin{tabular}{|l|c|c|c|}
\hline & Total Funding & FY17 Funding & FY18 Funding \\
\hline Task 1 & $\$ 700 \mathrm{~K}$ & $\$ 300 \mathrm{~K}$ & $\$ 400 \mathrm{~K}$ \\
\hline Task 2 & $\$ 700 \mathrm{~K}$ & $\$ 300 \mathrm{~K}$ & $\$ 400 \mathrm{~K}$ \\
\hline Task 3 & $\$ 750 \mathrm{~K}$ & $\$ 300 \mathrm{~K}$ & $\$ 450 \mathrm{~K}$ \\
\hline Task 4 & $\$ 1000 \mathrm{~K}$ & $\$ 350 \mathrm{~K}$ & $\$ 650 \mathrm{~K}$ \\
\hline Task 5 & $\$ 450 \mathrm{~K}$ & $\$ 100 \mathrm{~K}$ & $\$ 350 \mathrm{~K}$ \\
\hline Task 6 & $\$ 1000 \mathrm{~K}$ & $\$ 500 \mathrm{~K}$ & $\$ 500 \mathrm{~K}$ \\
\hline $\begin{array}{l}\text { Project/Task } \\
\text { Integration }\end{array}$ & $\$ 375 \mathrm{~K}$ & $\$ 200 \mathrm{~K}$ & $\$ 175 \mathrm{~K}$ \\
\hline Total & $\$ 4975 \mathrm{~K}$ & $\$ 2050 \mathrm{~K}$ & $\$ 2925 \mathrm{~K}$ \\
\hline
\end{tabular}




\section{Appendix A}

\section{INL-SRNL Aluminum Spent Nuclear Fuel Dry Storage Technical Issues Meeting, October 10, 2017}


Idaho National Laboratory - Savannah River National Laboratory Aluminum Spent

Nuclear Fuel Dry Storage Technical Issues Meeting Idaho National Laboratory

INL Research Center

2351 N. Boulevard, Conference Room \#120

Idaho Falls, ID

October 10, 2017

To join the Meeting:

https://bluejeans.com/505110934

To join via Room System:

Video Conferencing System: bjn.vc -or-199.48.152.152

Meeting ID : 505110934

To join via phone :

1) Dial:

+1.408 .740 .7256 (United States)

+1.888 .240 .2560 (US Toll Free)

+1.408 .317 .9253 (Alternate number)

(see all numbers - http://bluejeans.com/numbers)

2) Enter Conference ID : 505110934

7:30 Welcome Mike Connolly (INL), Lance Lacroix (DOE-ID/NE)

7:45 Meeting Objectives Mike Connolly (INL), Bill Bates (SRNL)

8:00 "Behavior/Chemistry of Oxyhydroxide.... Tedd Lister (INL), Kallie Metzger (SRNL) Layers for the Range of ASNF Fuel Designs and Dry Storage Configurations"

9:00 "Resolution of Radiolytic Gas Peter Zalupski (INL), Charles Crawford (SRNL) Generation for ASNF Oxyhydroxide Layers"

10:00 Break

10:15 “Combined Effect of Episodic .......... Hai Huang/Alex Abboud (INL), Tracy Rudisill (SRNL) Breathing and Radiolytic Generation of Potentially Corrosive Gases in Sealed and Vented Systems"

11:00 "Performance of Research Test Reactor Fuel in Existing Dry Storage Systems"

12:00 Lunch

1:15 "Effects of High Temperature .................... Rebecca Smith (INL), Kallie Metzger (SRNL) (i.e. greater than $100^{\circ} \mathrm{C}$ ) Drying on the Chemistry and Behavior of Oxyhydroxide Layers"

2:15 Summary/Actions/Path Forward Mike Connolly (INL), Bill Bates (SRNL), Lance Lacroix (DOE-ID/NE)

2:15 Summary/Actions/Path Forward Mike Connolly (INL), Bill Bates (SRNL), Lance Lacroix (DOE-ID/NE) 


\section{Task 1}

"Behavior/Chemistry of

Oxyhydroxide Layers for a Range of ASNF Fuel Designs and Dry Storage Configurations"

\section{Task 1}

Behavior/Chemistry of Oxyhydroxide Layers for a Range of ASNF Fuel Designs and Dry Storage Configurations

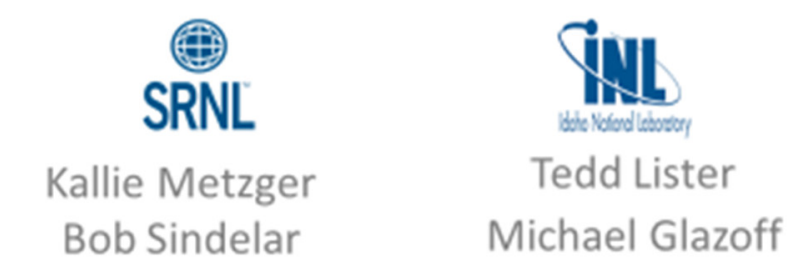




\section{Problem Statement}

Oxide/Oxyhydroxide formation and evolution is dependent upon temperature, heat flux, and water quality. Initial formation occurs during irradiation and continues through storage.

- Under what conditions do oxyhydroxides form and what are the mechanisms responsible for continued growth during pool storage?

- Are there mechanisms which could degrade aluminum oxide/oxyhydroxide layers during extended dry storage?

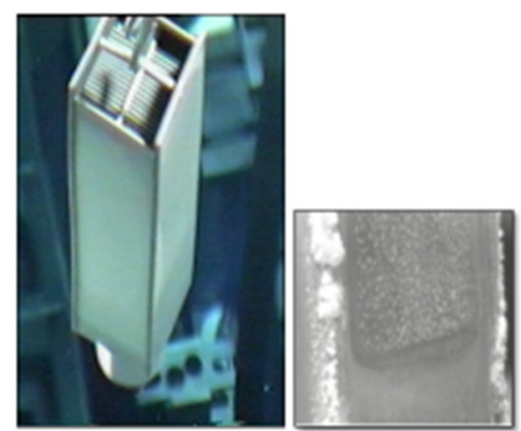

ASNE assembly after irrodationand atorage in good vater quality (let)' and poor quality water (right)

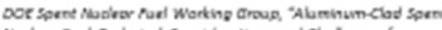

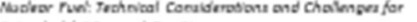

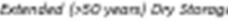

\section{Intended Outcomes}

- Understand behavior of oxides/oxyhydroxide layers under a set of conditions representative of wet and dry storage conditions.

- Characterize and test material properties for all oxides grown in this task.

- Provide defensible bounding thickness and growth rate of oxide layers depending upon fuel history (irradiation + storage). 


\section{Proposed Work Scope}

1. Investigate formation and growth kinetics: Hot wall immersion of Al alloy coupons will provide an opportunity to study the formation and behavior of oxides/oxyhydroxides under the influence of variable heat flux, water temperature, and water quality. Characterization and testing: Formed oxides will be characterized using XRD, XPS, cross-sectional metallography and mechanical properties as well as stability of oxide films will be measured.

2. Follow on tests to address environmental effects: Subsequent Aging tests can be performed on developed oxide films for a range of wet storage environments (effects of poor water quality, etc.). Additionally, behavior of oxides in dry storage will be tested in order to assess oxide-water chemistry and possibility for accelerated corrosion including effects of radiolysis. The influence of film breach on corrosion growth rates in both wet and dry storage will also be investigated in this effort.

\section{Investigate Formation and Growth Kinetics for Variety of Operating and Storage Conditions}

Identify bounding heat flux and temperature conditions representative of reactor operation and post-discharge storage.

- Select applicable Al alloys for testing and document thermal treatments used in alloy fabrication.

"Inquiry regarding relewant current fuel inventory may be supportod by efforts in task 4.

- Perform heat flux immersion and/or Al anodization experiments on Al alloy sample plates under controlled conditions to investigate influence of heat flux, water temperature, and vater quality $(\mathrm{pH})$ on oxide/oxyhydroxide formation and structure.

"Additional oxides can be grown on Al substrates in this step to suppoly tosting materials for enveronmental testing as wells as testing required in tasks 2 and 5 (radiolytic gas generation and drying tests)

Following grovth and immersion testing, composition and thickness of oxyhydroxides vill be characterized using a variety of techniques including but not limited to TGA, XRD, XPS, cross sectional metallography.

- Mechanical properties of films will be measured to assess vihat externally applied forces the film can withstand before being irreversible disrupted.

- Tests will be performed to examine film integrity when presented with stresses (compression, tension, and torsional) and if oxide film spalling is possible.

"A subset of follow on immorsion tests in will investigate the influence of breaches, scratches or othor coxide film damage on the performance and behyvior of attendant film during resctor service and storage. 


\section{Follow on tests to address other environmental effects:}

- Additional immersion tests of laboratory-grown oxides can replicate a variety of wet storage conditions. (Initial immersion tests allowed for the formation and growth of oxides on substrates.)

"This two step experimental process provides an opportunity to study oxide growth as it relates to formation in reactor and possible transition as it relates to wet storage in wideranging water quality.

- Investigation chemical interactions and aging reactions involving water with aluminum oxides including effects of radiolysis. Will include modeling and experimental efforts to provide data for both sealed and vented configurations.

"Includes interface task with Topic 2 as well as inform Topic 3 of anticipated gas generation due to aging. Use conditions identified in Topic 3.

- This effort will also examine mechanisms for accelerated degradation of aluminum oxide films and determine environmental conditions required to become active. (Localized corrosion mechanisms studied may include crevice corrosion, galvanic corrosion, influence of latent microbial or salt films, and radiolytic influenced corrosion.)

"This series of experiments provides an opportunity for conditions identified in task 3 (environmental modeling) to be tested.

\section{Synthesis of Results:}

- As results of oxide growth characterization and testing become available, a team will work to resolve kinetics of oxide/oxyhydroxide formation and behavior.

- Formation and behavior models will be delivered to Task 3 team to support meso-scale modeling efforts.

- Stability of phases and potential for degradation will be assessed as it relates to extended dry storage. 


\section{Schedule and Cost of Activities}

\begin{tabular}{|c|c|c|}
\hline Months $0-2$ & $\begin{array}{l}\text { Identify Al alloys of interest. Identify testing conditions representative of } \\
\text { oxide formation in reactor as ivell as conditions representative of a } \\
\text { variety of possible wet and dry storage configurations (heat flux, } \\
\text { temperature, water quality, etc.) }\end{array}$ & $75 K$ \\
\hline Months $2-9$ & Grow oxides on Al substrates using conditions previously identified. & $150 \mathrm{~K}$ \\
\hline Months 9-18 & $\begin{array}{l}\text { Characterize as-formed oxides. Test mechanical properties and stability of } \\
\text { as-formed oxides. }\end{array}$ & $200 \mathrm{~K}$ \\
\hline Months $12-18$ & $\begin{array}{l}\text { Subject a collection grown oxides to additional immersion testing to } \\
\text { replicate effects of wet-storage. Investigate corrosion associated with dry } \\
\text { storage conditions (e.g. accelerated galvanic corrosion, etc.). Test oxide } \\
\text { film grovth rates following breach of film. Perform follow-on } \\
\text { characterization and testing. }\end{array}$ & $300 \mathrm{~K}$ \\
\hline \multirow[t]{2}{*}{ Months 9-18 } & $\begin{array}{l}\text { As results becomes available, synthesize data for oxide/oxyhydroxides } \\
\text { formation and growth kinetics. }\end{array}$ & $100 \mathrm{~K}$ \\
\hline & Total: 18 months & $-825 \mathrm{~K}$ \\
\hline
\end{tabular}

* A portion of budget from task 1 can be used to provide as formed oxide specimens to tasks 2 and 5

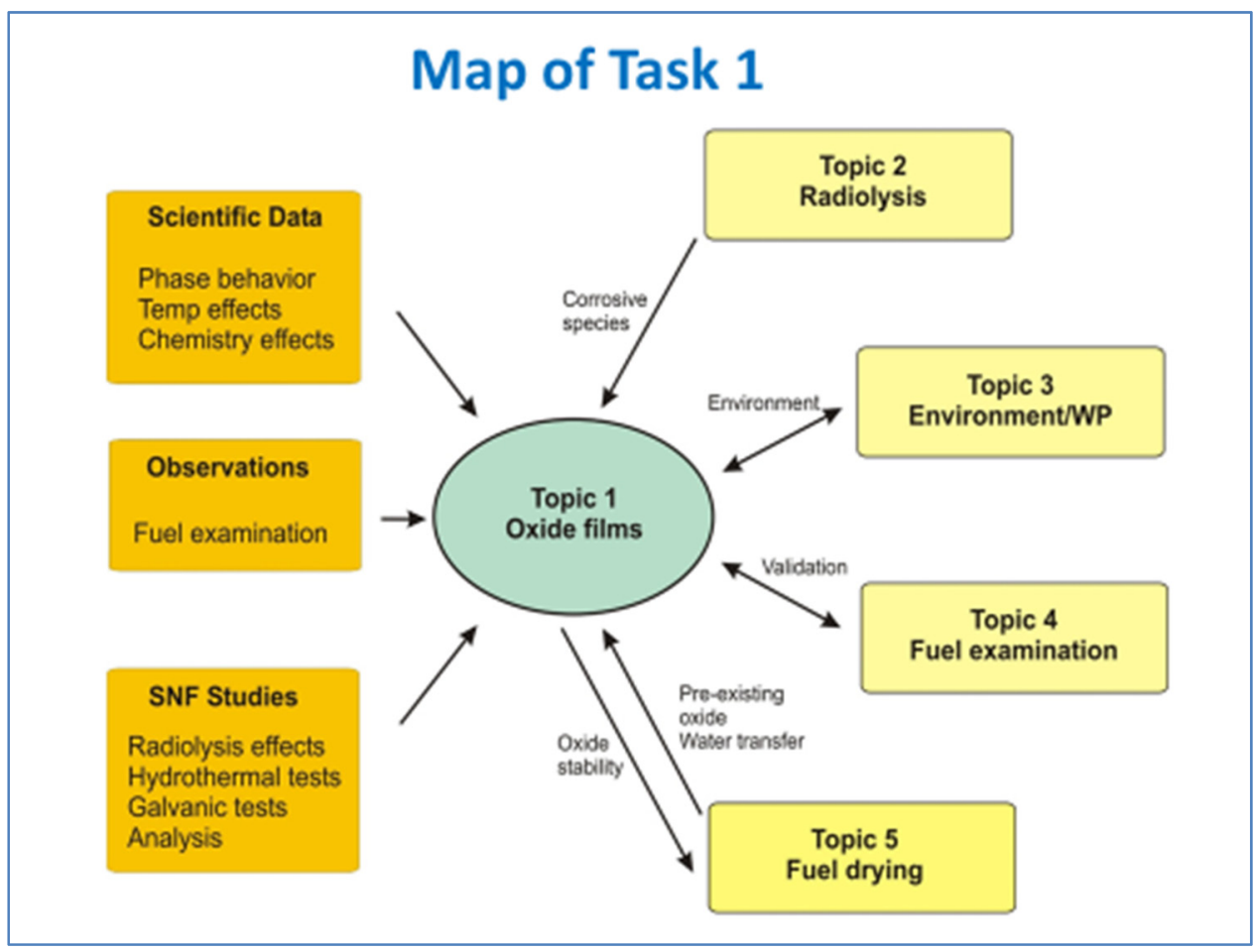




\section{Meshing Task 1 Scope With Other Areas}

1) What environments are onticipated in the vorious designs, storage locotions and fuel age/designs?

Task 3: In order to assess what will happen to the oxide, a knowledge of the temperature, humidity and potential crevice conditions is required. A model that defines possible environments would be an important feed.

\section{2) What radiolysis products are possible?}

Task 2/3: In some cases, such as nitric acid generation, it might be possible to experimentally simulate in a non-rad condition. Suggest interface task with Topic 2 where effects of radiolysis are tested.

3) What is the starting condition of fuel?

Task 4/5: What are the anticipated starting conditions of fuel cladding and can it be simulated? Will have to rely on existing data/observations. What are the anticipated water carryover after drying which can participate in reaction?

4) What physical damage history might fuel accumulate during lifetime?

Task 4: While moving fuel to dry storage should be done with minimal damage, there is potential for mechanical stress placed on the oxide films during emplacement. This could occur through sliding, rubbing, vibration, knocking and weight load. Another area that will rely on historic data/observations. PIE performed in Task 4 may also be a verification tool for oxide formation observed in Task 1.

"*Additionally, oxides grown on Al alloy coupons in task 1 can be used for testing radiolytic gas generation in task 2 as well as dehydration testing (TGA, drying demo) in task 5 .

\section{Discussion?}




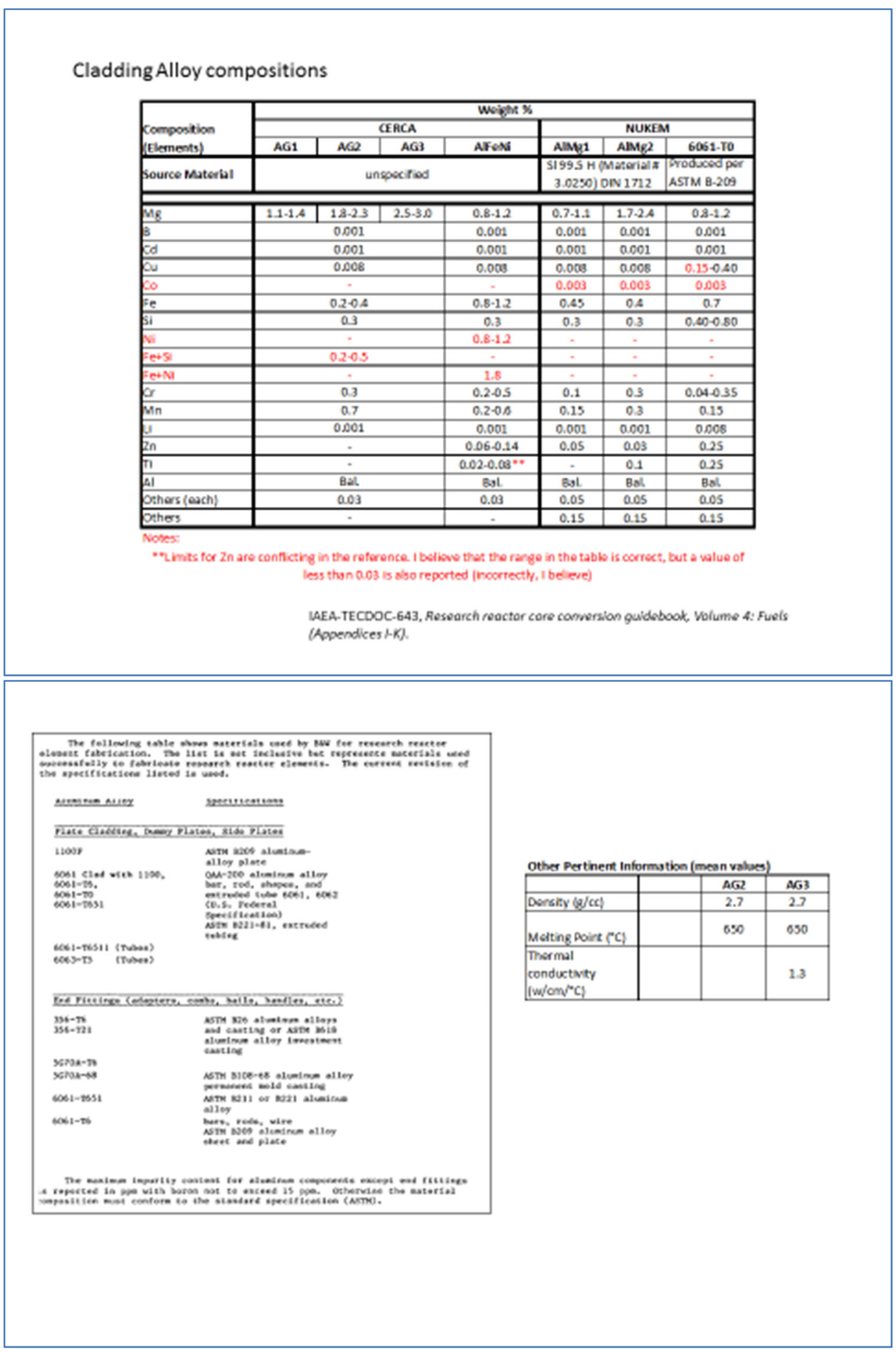




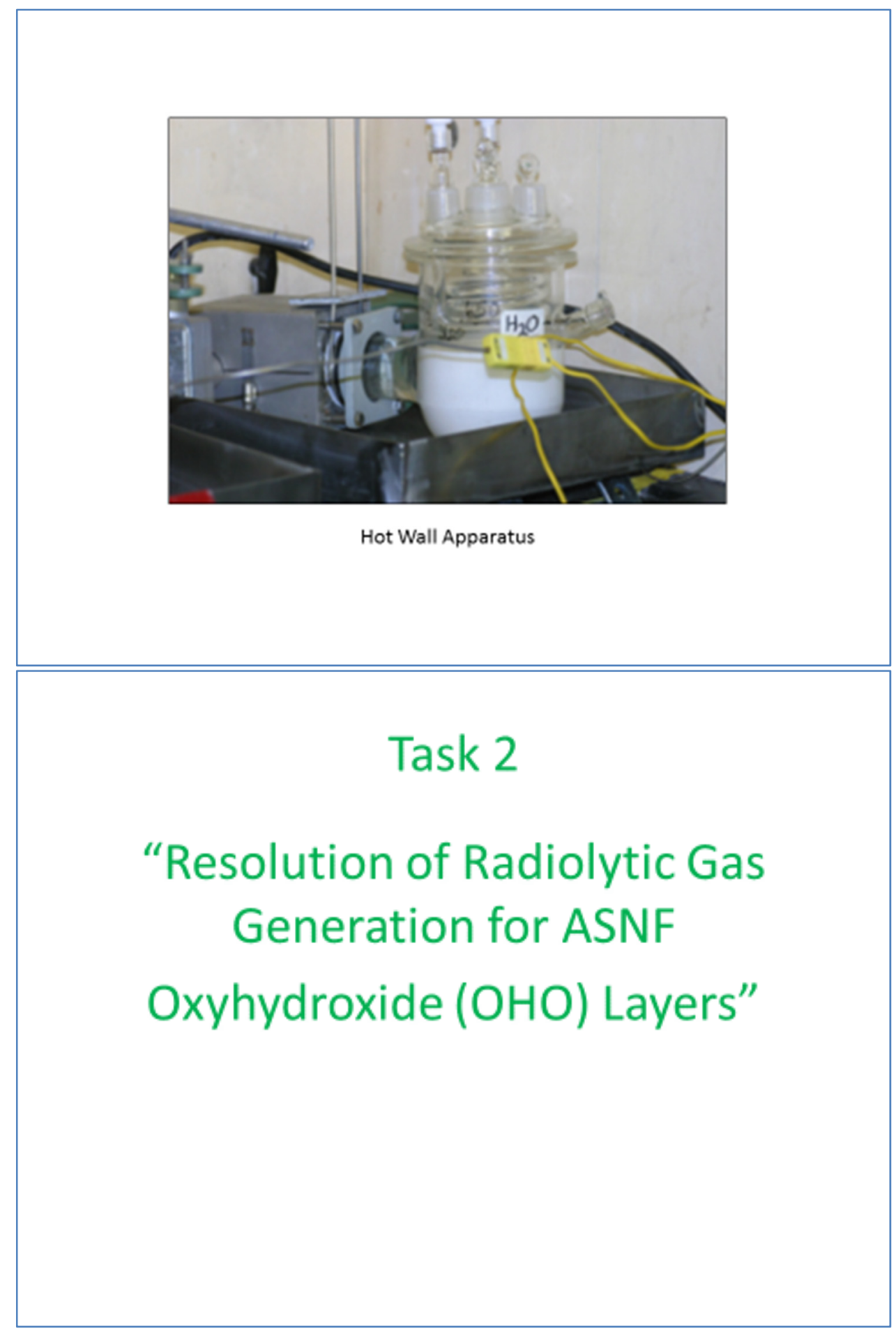




\section{Aluminum Clad SNF: Knowledge Gaps and Technical Needs}

\section{Task 2: Resolution of Radiolytic Gas Generation for ASNF Oxyhydroxide (OHO) Layers}

Gregory P. Horne, INL: 6 years of experimental and computational radiation chemistry research experience

Peter Zalupski, INL: 16 years of experience in radiochemistry, solution chemistry, thermodynamic equilibria, and applied radiation chemistry at the back end of the nuclear fuel cycle

Charles Crawford, SRNL: 20 years of experience in experimental radiation chemistry pertaining to radioactive waste systems at SRS

Christopher Verst, SRNL: 5 years of experience in spent fuel characterization, radiation damage, and aging management of fuel disposition facilities

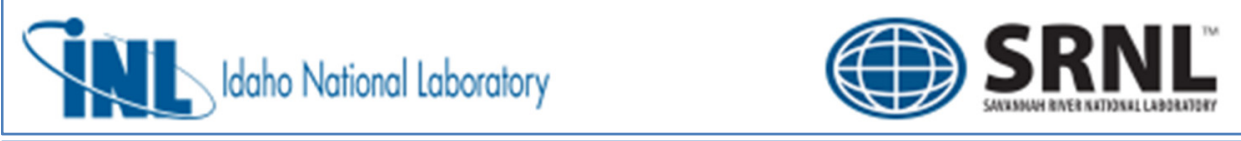

\section{Problem Statement}

Radiolytic generation of gases ${ }^{(1,2)}$ from solid and gaseous sources presents potential challenges for the long term storage of ASNF ( $>50$ years) in the form of: pressurization, ${ }^{(3)}$ depressurization, formation of flammable gas mixtures, ${ }^{(1,2)}$ embrittlement, ${ }^{(4)}$ and chemical corrosion. ${ }^{(5,6)}$

\section{Research Questions}

What are the important radiolytic species produced in sealed and vented ASNF container configurations, and what are their generation rates as a function of storage conditions?

Will the experimental radiolysis measurements confirm the existing literature data, ${ }^{(7,8)}$ supplement it and validate the predicted radiation-induced chemical equilibria?

(1) Wettron, R. Radolysis Model Senstrinty Andysis for s Used Fuel Storage Crnister. FCRD-UFD-2013-000357, 2013

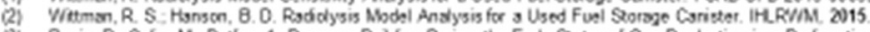

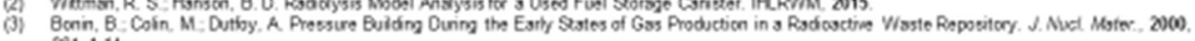
$289,1-14$

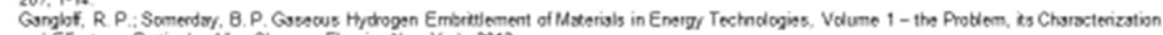
and Efects on Particulyr Aloy Classes. Evener New York, 2012

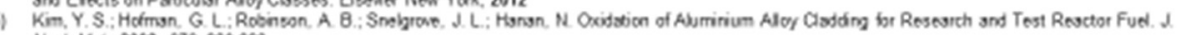
Nud Mrt. 20(6). 378, 220-228

Comovion of Research Reactor Auminium Clad Ssent Nuchas Fual in Water. MEA-TECOOC-1637, 2609

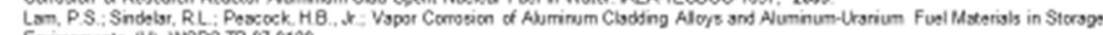




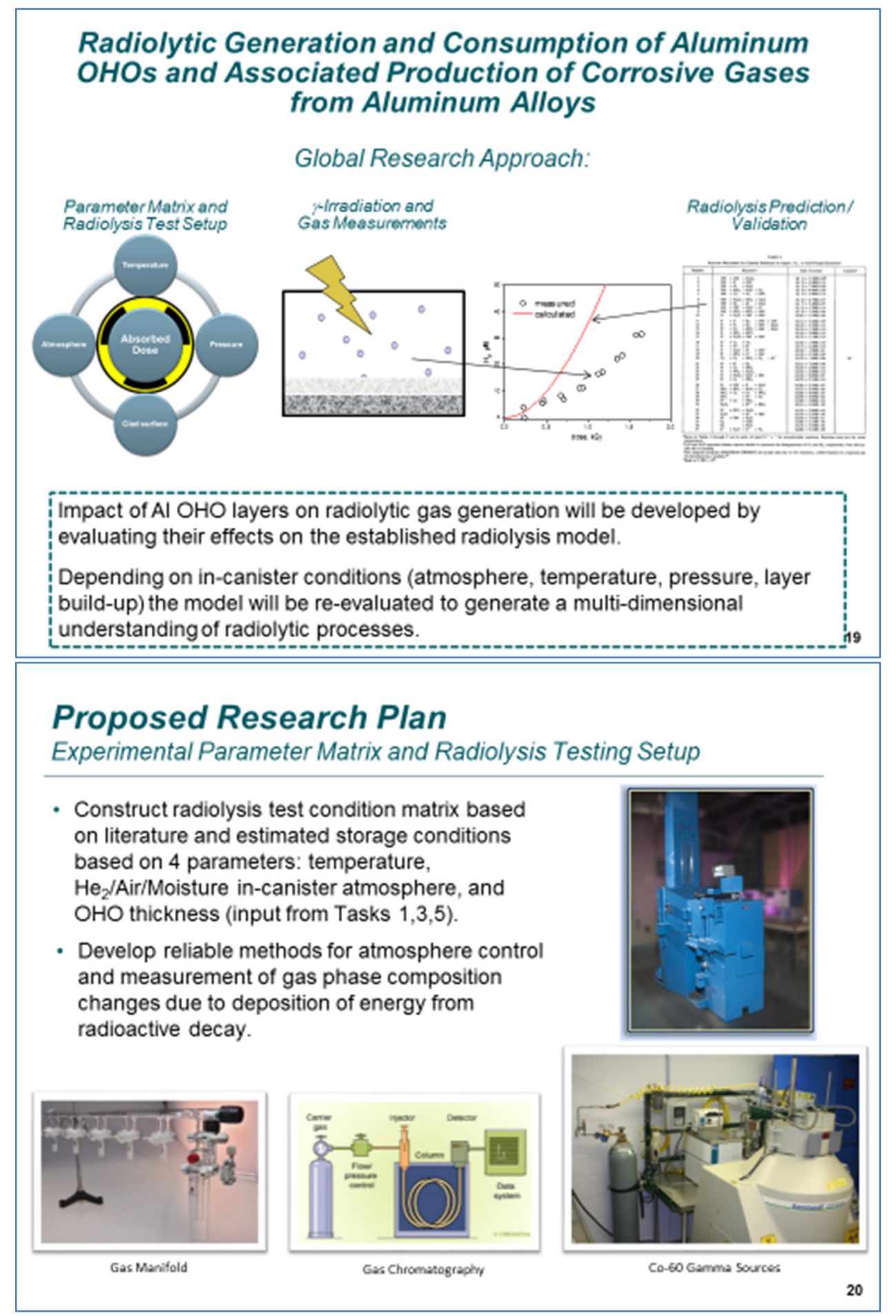




\section{Proposed Research Plan}

$\gamma$-Irradiation and Gas Measurements

- Gamma irradiation of flame sealed vials / Parr vessels containing controlled gas / water vapor mixtures composition as a function of parameter matrix.

- Analyses for complete gas composition using gas chromatography (GC) techniques for baseline and confirmatory G-values of potential container gases.

- Gamma irradiation / GC analyses of vials / vessels containing aluminum coupons with / without oxyhydroxide films to estimate effects of materials on radiolytic gas production rates (calculation of G-values, dose-yield curves as a function of test parameters).

\section{Proposed Research Plan}

Radiolysis Prediction / Validation

- Experimental results will be predicted using previously developed multi-scale kinetic equilibrium set.(2) The derived radiolytic degradation rates and gas compositions will be verified by follow-on irradiation studies.

- Well characterized Gibbsite/Boehmite samples formulated to exemplify reactor grown specimens (Task 1) will undergo high dose radiolysis testing to ensure consistent, predictable behavior for conditions selected to match PIE candidates (Task 4).

- Irradiated coupons will be available for structural studies, surface chemistry studies (Task 1).

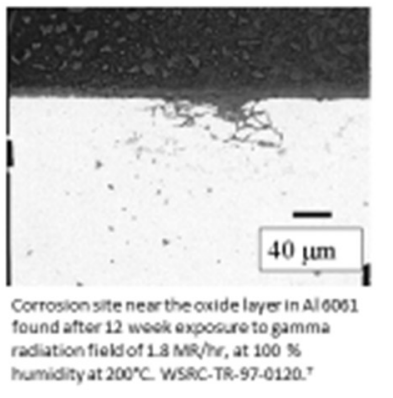




\section{Outcomes}

- Radiolytic yields (G-values) and concentration dependencies for potentially problematic and corrosive gases (e.g. $\mathrm{H}_{2}$ and $\mathrm{NO}_{x}$ ) as a function of all key parameters influencing radiolytic gas generation.

- Impact of radiolytic damage on aluminum alloys when results interfaced with Task 1.

- Predictive indication of radiolytic corrosion of Al clad if results correlated to structural studies.

- A predicting multi-scale kinetic tool, providing quantitative mechanistic insight into the in-cask radiation chemistry of ASNF, which can be used as a component of multi-physics computational fluid dynamics modeling effort (Task 3).

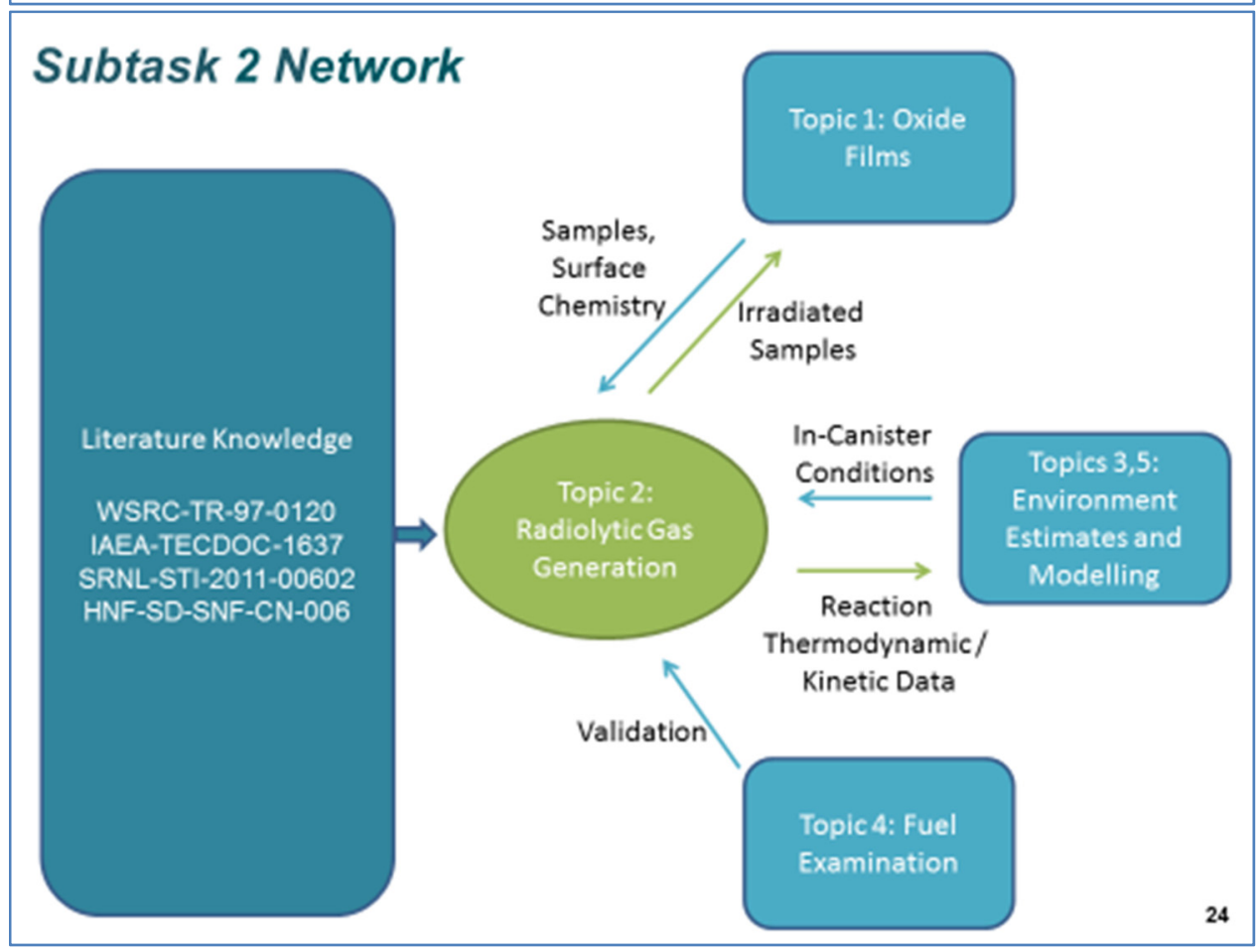




\section{Current Relevant ASNF Knowledge}

- Thermal and chemical corrosion of ASNF is well understood, ${ }^{(5.6)}$ as demonstrated by the IAEA Corrosion of Research Reactor Aluminium Clad Spent Nuclear Fuel in Water global study. (6)

- Radiation induced corrosion and accompanied gas generation is less understood for the ASNF system as a whole, i.e. combined radiolytic effects and interactions between solid and gaseous phases.

- Previous irradiation studies have focused on various components of the problem, although the insight provided is critical to understand the problem as a whole. ${ }^{(9-12)}$

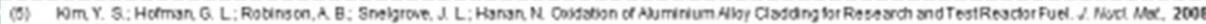
$378,220-223$

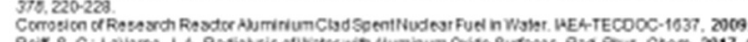

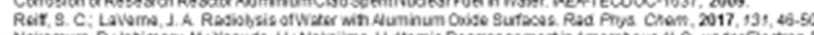

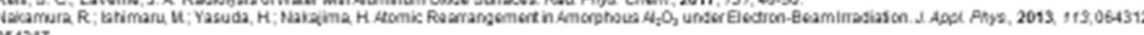

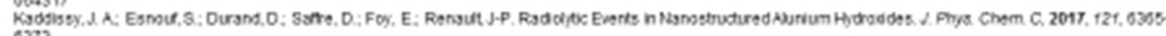

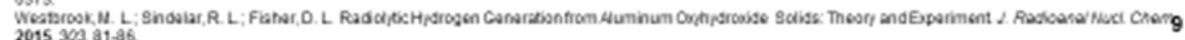

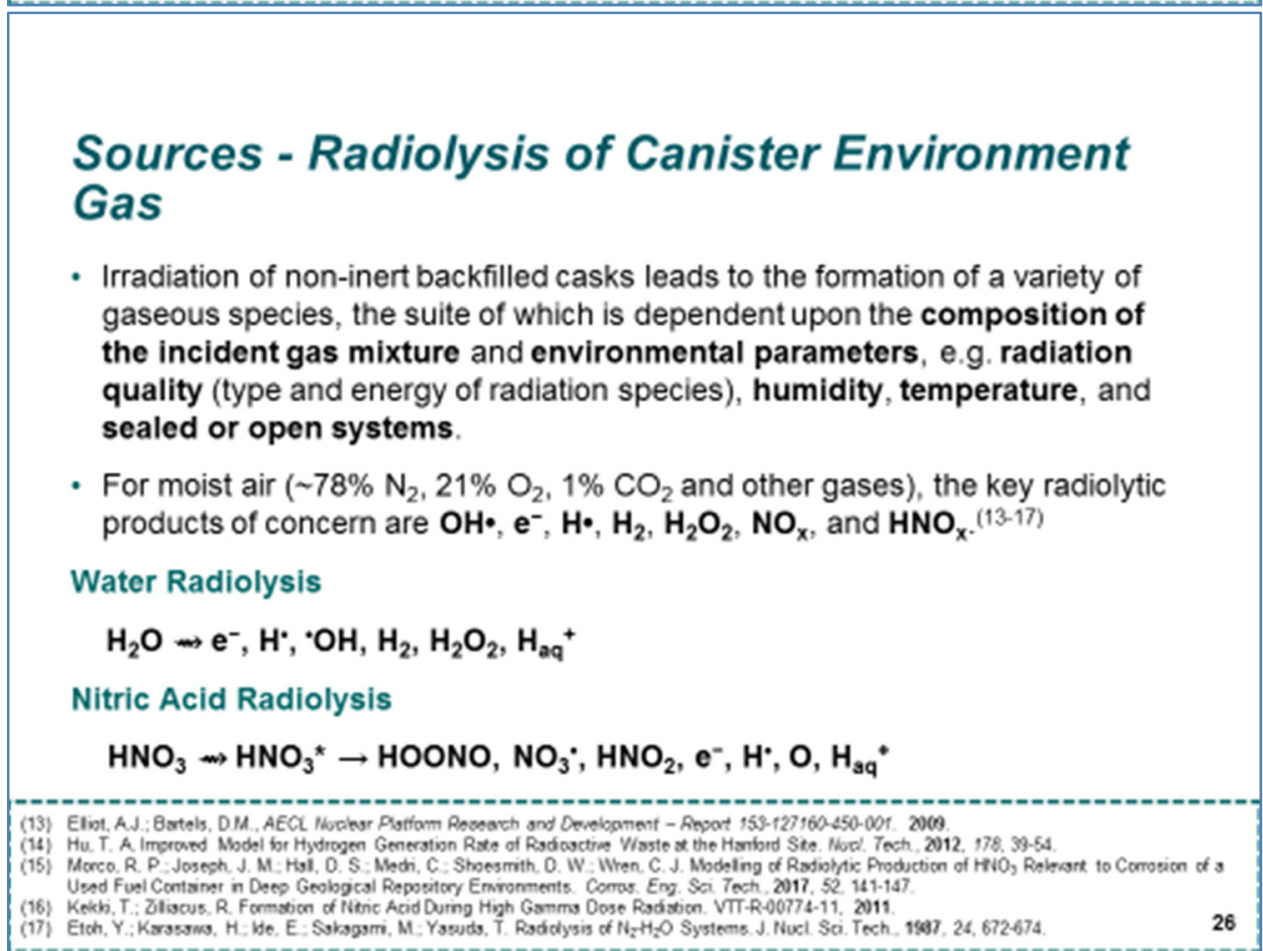




\section{Sources - Radiolysis of Oxyhydroxides}

- Irradiation of the ASNF surface will also contribute to the formation of radiolytic species, some of which will be gaseous in nature. ${ }^{(10.12,18-21)}$

- Oxyhydroxides grow on ASNF as a consequence of corrosion processes in the presence of aqueous solutions and/or water vapor. The resulting mineral phases are dependent on a number of conditions, e.g. temperature, coolant quality and $\mathrm{pH}$.

- These mineral phases have been shown to generate $\mathrm{H}_{2}$ and be consumed in the process to the extent of aluminum metal formation, thereby providing an additional highly reactive surface..$^{(12,18)}$

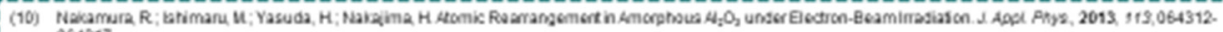
064317

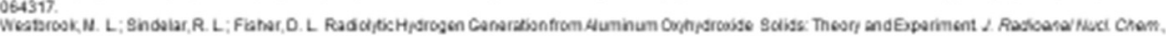
2015. $303,81-86$

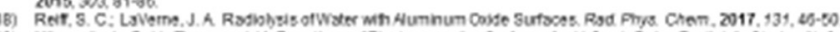

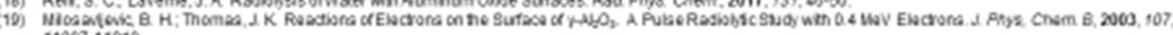

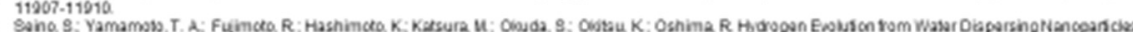

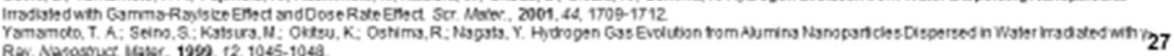

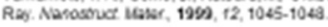

\section{Activities and Schedule}

- Task 1: Comprehensive evaluation of literature.

- Task 2: Experimental design: irradiation vessels, atmosphere control, temperature control, pressure control, Al coupon diversity

- Task 3: Baseline $\gamma$-irradiations/gas production analyses

- Task 4: Development of radiolysis equilibrium set

- Task 5: $\gamma$-irradiations / gas production analyses - corroded Al clad

- Task 6: Revision of radiolysis equilibrium set

\begin{tabular}{|c|c|c|c|c|c|c|c|}
\hline Task & Q1 & Q2 & Q3 & Q4 & Q5 & Q6 & \$ \\
\hline 1 & X & & & & & & $20 k$ \\
\hline 2 & X & X & & & & & $80 k$ \\
\hline 3 & & $\mathrm{X}$ & $\mathrm{X}$ & $\mathrm{X}$ & & & $160 \mathrm{k}$ \\
\hline 4 & & $\mathrm{X}$ & $\mathrm{X}$ & $\mathrm{X}$ & $\mathrm{X}$ & & $40 \mathrm{k}$ \\
\hline 5 & & & & $\mathrm{X}$ & $\mathrm{X}$ & $\mathrm{X}$ & $160 \mathrm{k}$ \\
\hline 6 & & & & & & $\mathrm{X}$ & $40 \mathrm{k}$ \\
\hline $\mathbf{\$}$ & $60 \mathrm{k}$ & $120 \mathrm{k}$ & $60 \mathrm{k}$ & $80 \mathrm{k}$ & $100 \mathrm{k}$ & $80 \mathrm{k}$ & $500 \mathrm{k}$ Total \\
\hline
\end{tabular}




\section{Task 3}

"Combined Effect of Episodic Breathing and Radiolytic Generation of Potentially Corrosive Gases in Sealed and Vented Systems"

Task 3:Combined Effect of Episodic Breathing and Radiolytic Generation of Potentially Corrosive Gases in Sealed and Vented Systems

Points of Contact

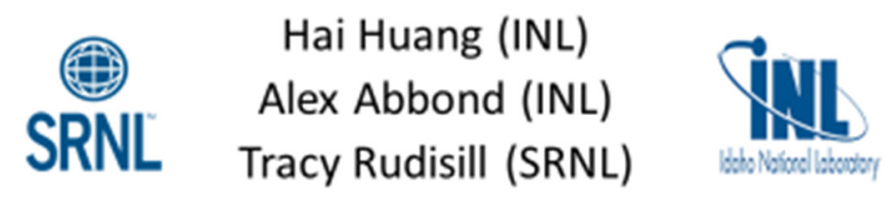
Kallie Metzger (SRNL) 


\section{Problem Statement}

- What are the coupled effects of episodic breathing and the radiolytic production of corrosive gases in both vented and sealed storage systems?

- Existing models for in-canister radiolytic generation of corrosive gases:

- Treated as homogenous batch reactors:

- Equilibrium/lisnosc.

- Nonlinear ODEs ss functions of dose rate, G-values, temperature humidin, Ess concentrations etc.

- Norigorous coupling betwson gas phazs, condonsod water phase and motal surtaces.

- Exchanges of reactants/products, moisture and heat for vented/unsealed system via episodic breathing will:

- Shift the reaction equilibrium and pathways in both filling gas and Al oxyhydroxide layers;

- Affect the spatial/temporal distributions of in-canister temperature, gas concentrations, humidity, which are important environmental constrains;

- The coupling effects are largely unknown.

- Need multiscale multiphysics models that couple together:

- Canister-scale gas phase transport of heat and mass;

- radiolytic gas production kinetics of Al oxyhydroxide layer and air

- Predict the gas phase concentration and the condensed phase water chemistry for aluminum-clad fuel in sealed and open systems

- development of the protocol for water vapor and cover gas compositions used in capsule irradiation experiments

- Model validations

\section{Proposed Modeling Effort -Phased Approach}

- Determine storage system conditions pertinent to radiolysis production rates:

- Identify range of humidity, ambient temperature, and salinity based on diurnal/annual changes at relevant storage locations

- Generate radiative heat source terms as a function of fuel type, configuration, and burnup/cooling time

- Estimate dose rate, and possibly establish lower/upper bounds

- Identify corrosive species of interest and bounding moist air radiolytic generation rates from literature

- Assess likelihood of condensate formation within the overpack and its relative impact on canister corrosion rates

- Make use of extensive radiolysis kinetic modeling efforts for other applications:

- Many gas phase reactions and G-values will be the same as typically used for atmospheric chemistry, gas treatment applications, and radiolysis of steam in nuclear power plants

- Radiolysis model analysis for commercial used fuel storage canister (Wittman and Hanson, PNNL)

- Other sources of data?

- Handling chemical reactions:

- Identify major \& rate-limiting radiolysis reactions

- Identify reactions that can be ignored or modeled at equilibrium for the interested storage time scales

- Formulate the film reactions into surface reactions

- Add data from aluminum oxyhydroxide radiolysis experiments as it becomes available

- Use gas generation model as the internal source term for a multiphysics computational fluid dynamics (CFD) models for vented storage canister 


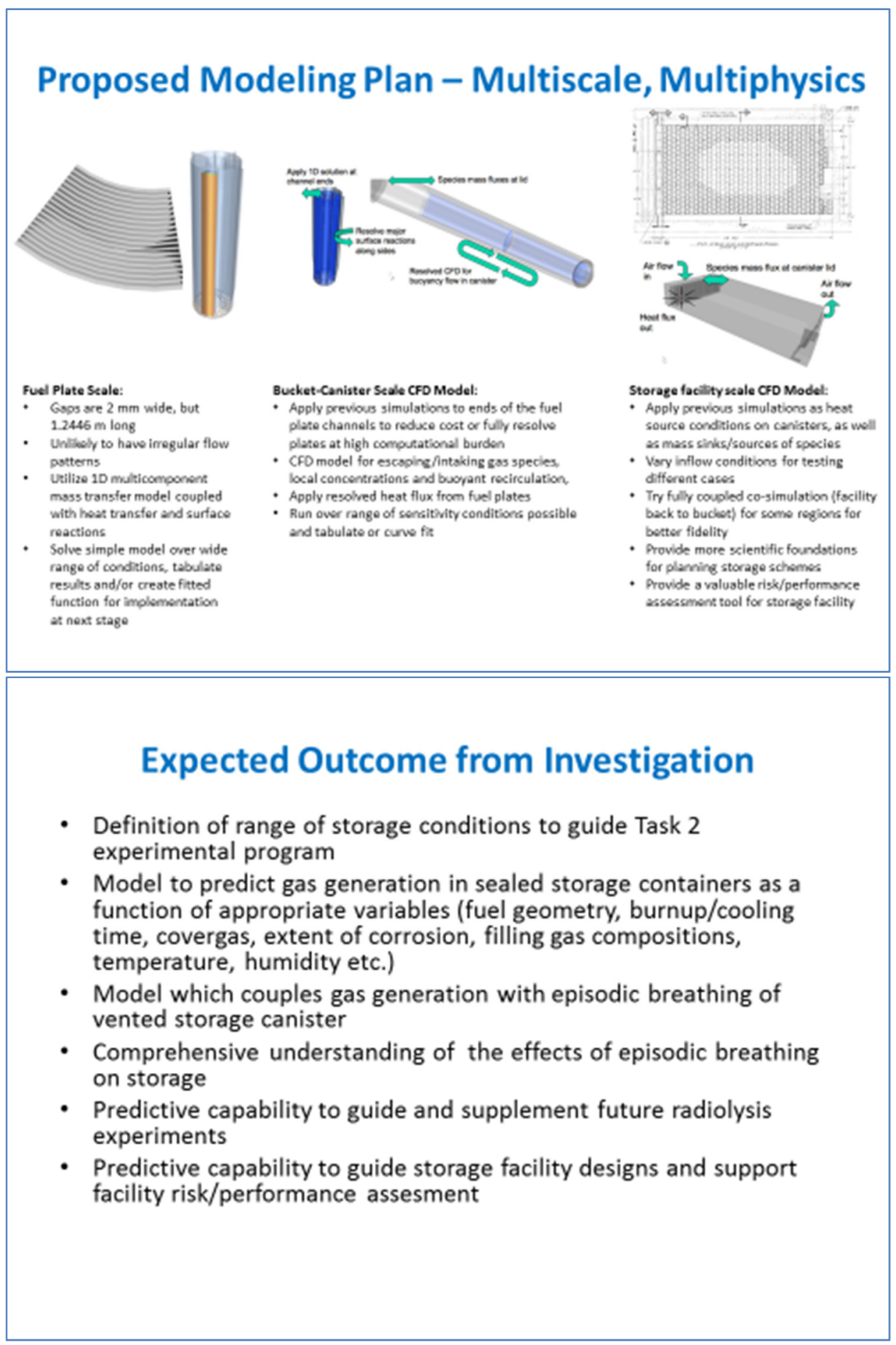




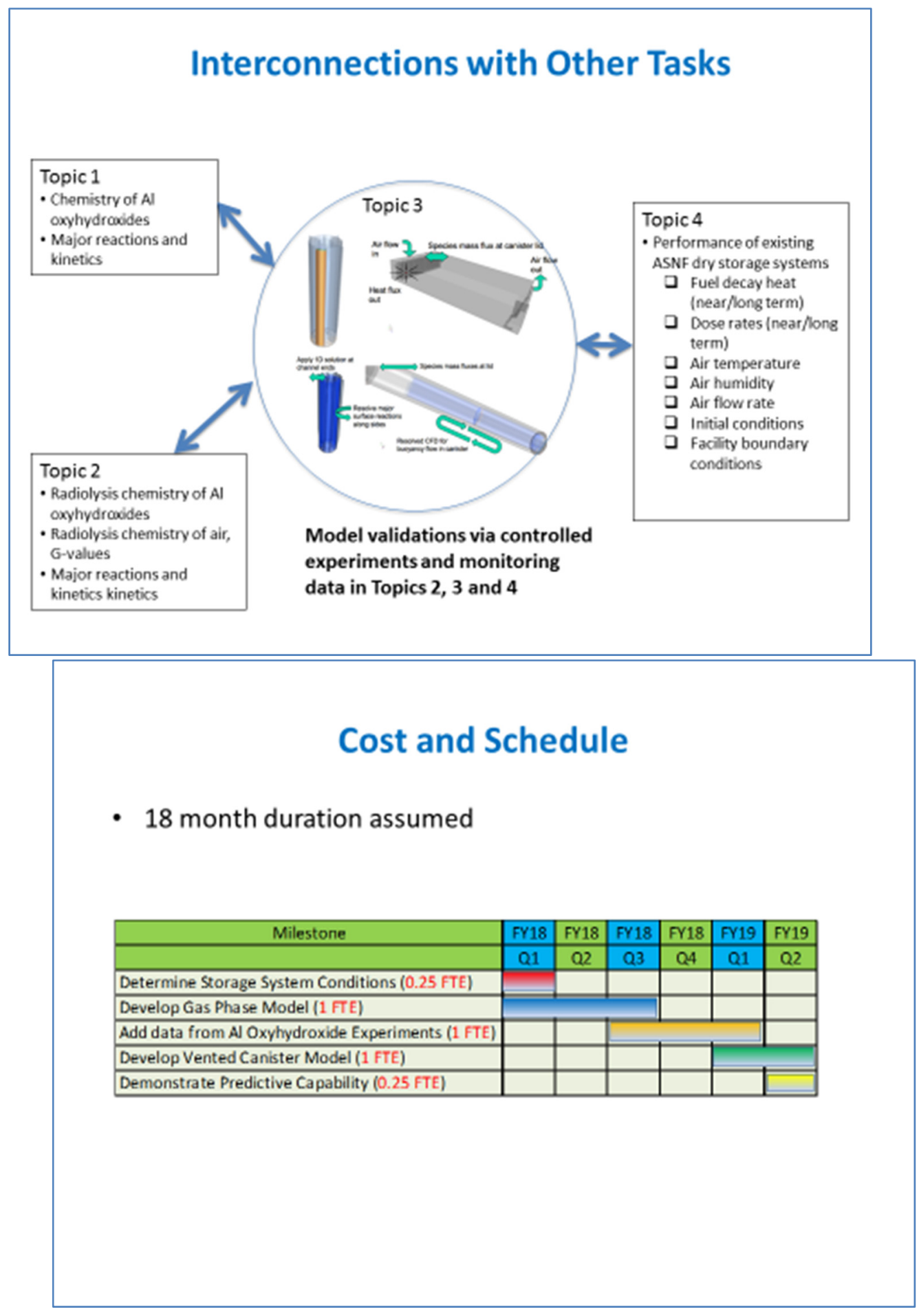




\section{Backup slides}

\section{Multi-scale Model}

- Couple different scales of the system

- Start 1-way coupled

- Both temporally and spatially

- Simplest model at fuel plate channels

- ATR8 bucket simulation using fuel plate channel approximations in combination with surface chemistry

- Facility simulation using heat sources and mass sources/sinks from conditions in bucket/canister simulation

- Reduced Order Mechanism (ROM) for radiolysis reactions

- Over 100 reactions/species creates too many PDEs to resolve

- ROM for most important, reduce cost

- Identify time-scale separations, rate-controlled constrained equilibrium (RCCE resolves some reactions, assume others always at equilibrium) or similar approach 


\section{Topic 3 Some Research Questions}

- What are detailed temperate field (and spatial-temporal evolutions) inside and outside canisters), under episodic breathing conditions

- What are detailed water vapor concentration field (and spatial-temporal evolutions) inside and outside of canisters

- What are the detailed concentration fields of $\mathrm{H} 2, \mathrm{O} 2, \mathrm{~N} 2$ and other radiolytically generated corrosive products such as $\mathrm{HNO} 3, \mathrm{CO}, \mathrm{N2O}$, and $\mathrm{NO} 2$ inside and outside canisters; predicting the gas species concentrations over extended period of storage time

- Amount of the condensed water and spatial-temporal evolutions on the surfaces of carbon steel canister and aluminum-claddings

\section{Multi-scale Model}

- Couple different scales of the system

- Start 1-way coupled

- Both temporally and spatially

- Simplest model at fuel plate channels

- ATR8 bucket simulation using fuel plate channel approximations in combination with surface chemistry

- Facility simulation using heat sources and mass sources/sinks from conditions in bucket/canister simulation

- Reduced Order Mechanism (ROM) for radiolysis reactions

- Over 100 reactions/species creates too many PDEs to resolve

- ROM for most important, reduce cost

- Identify time-scale separations, rate-controlled constrained equilibrium (RCCE resolves some reactions, assume others always at equilibrium) or similar approach 


\section{Fuel Plate Scale}

- Gaps are $2 \mathrm{~mm}$ wide, but $1.2446 \mathrm{~m}$ long

- Unlikely to have irregular flow patterns

- Utilize 10 multicomponent mass transfer model coupled with heat transfer and surface reactions (possibly Relap?)

- Solve simple model over wide range of conditions, tabulate results and/or create fitted function for implementation at next stage
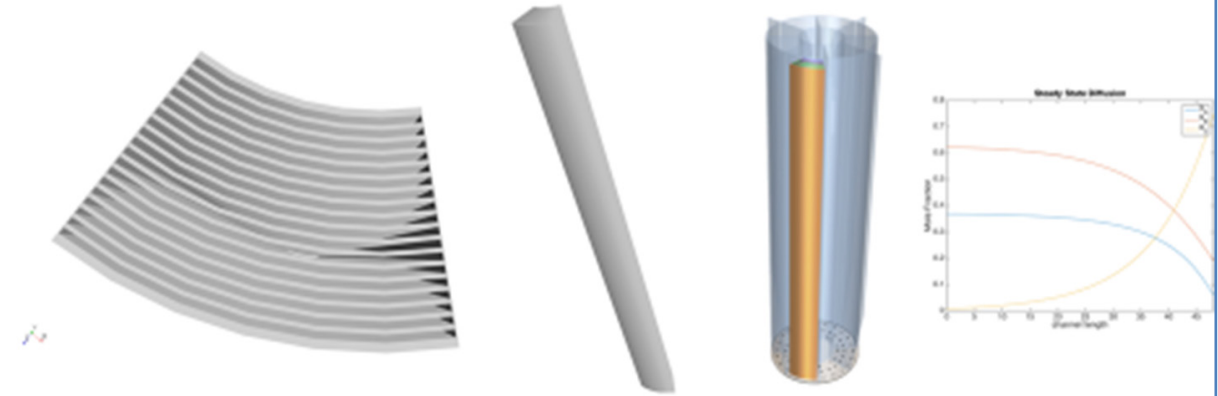

\section{Bucket/Canister Scale}

- Apply previous simulations to end of the fuel plate channels to reduce cost or fully resolve plates at high computational burden

- CFD model for escaping gas species, local concentrations and buoyant recirculation, apply resolved heat flux from fuel plates

- Run over range of sensitivity conditions possible and tabulate or curve fit

Apply 10 solution at channel ends
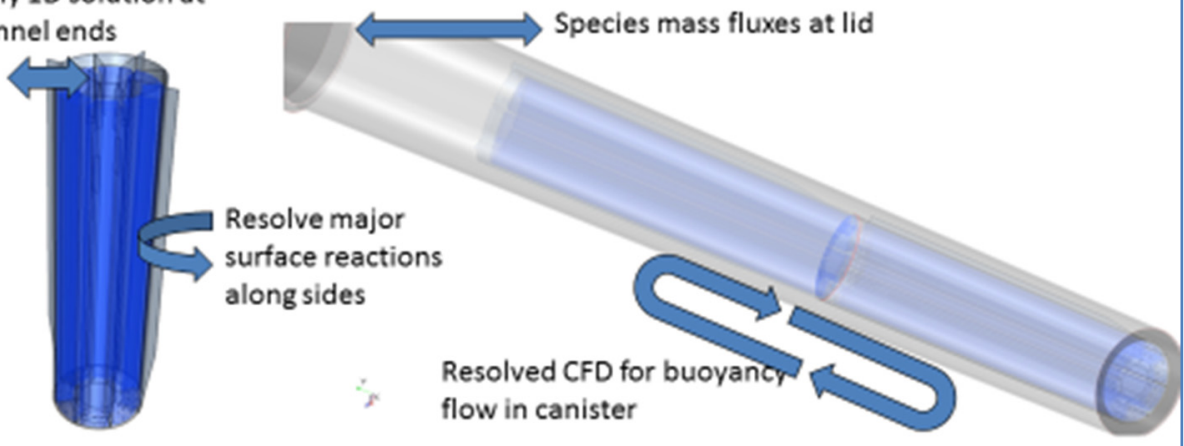


\section{Facility Scale}

- Apply previous simulations as heat source conditions on canisters, as well as mass sinks/sources of species

- Vary inflow conditions for testing different cases

- Try fully coupled co-simulation (facility back to bucket) for some regions that may give bad conditions for better fidelity

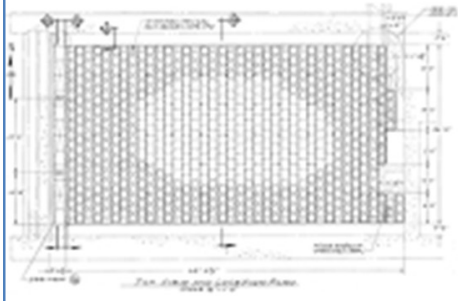

Air flow 5 Species mass flux at canister lid

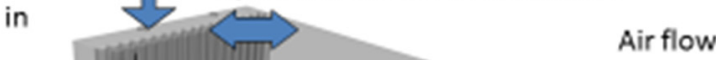

Heat flux out

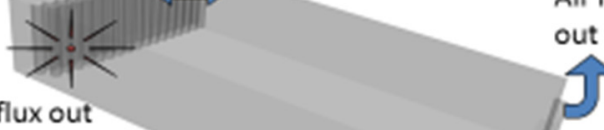
out

Task 4

"Performance of Research Test Reactor Fuel in Existing Dry Storage Systems" 


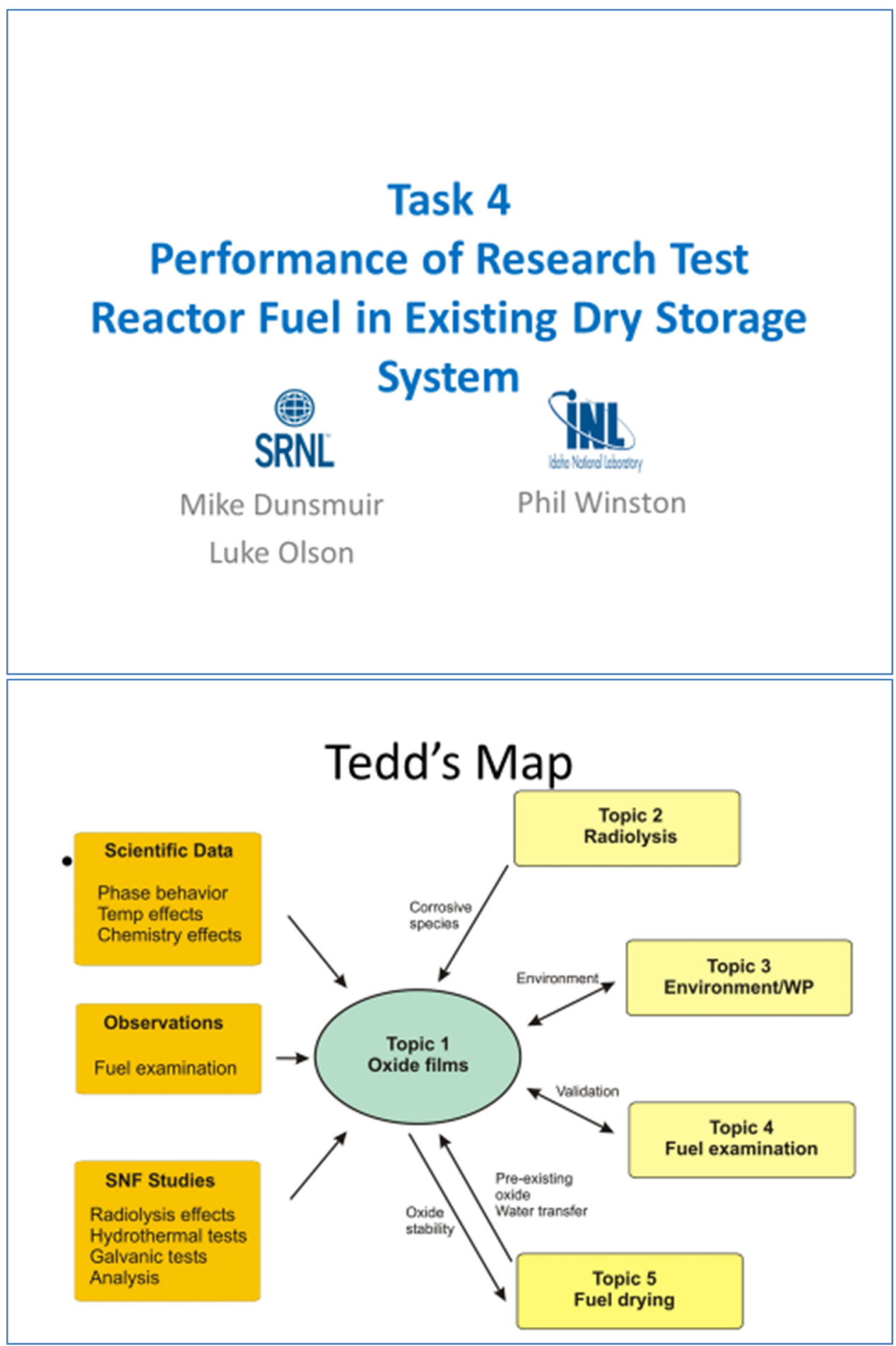




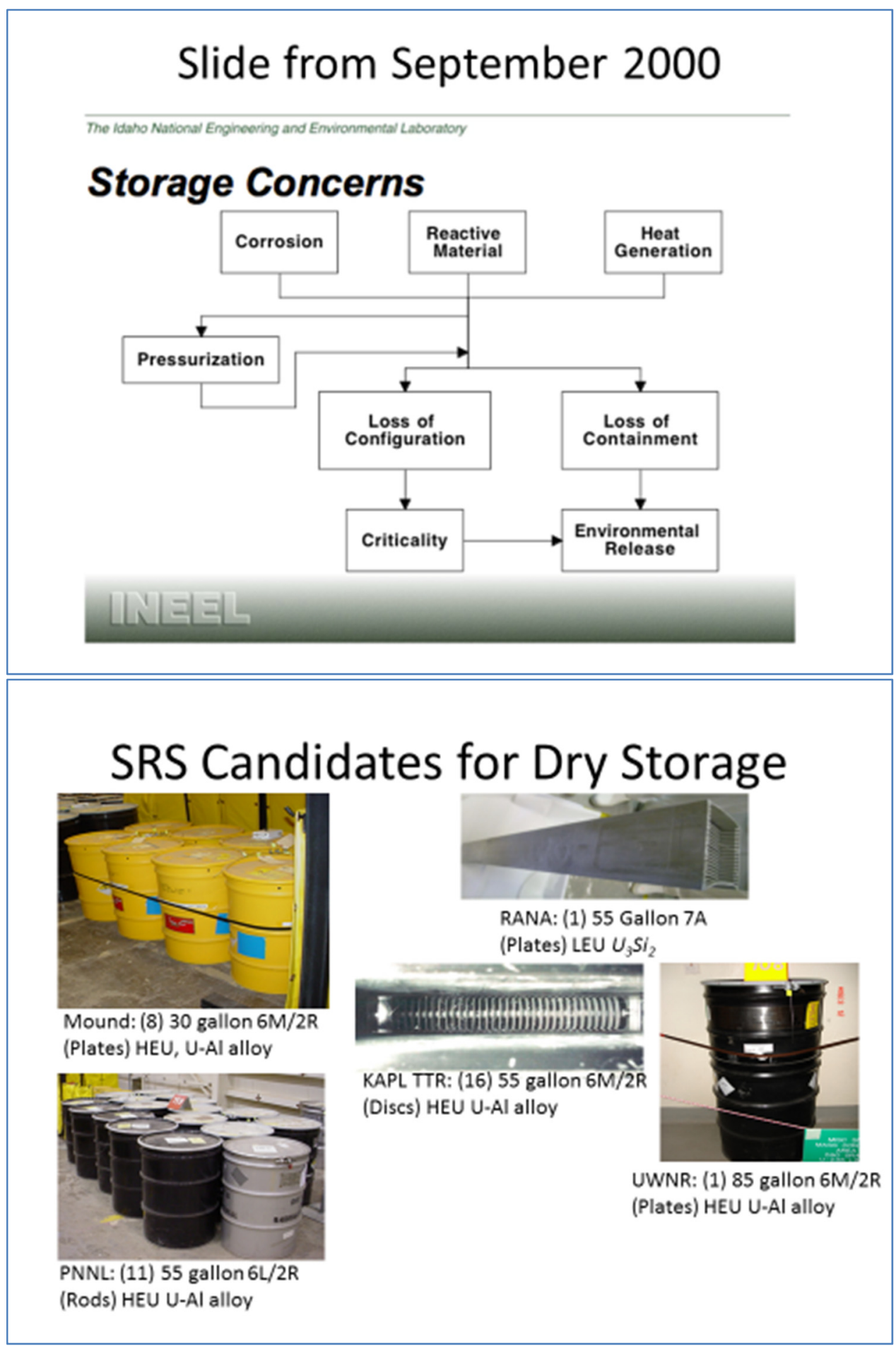




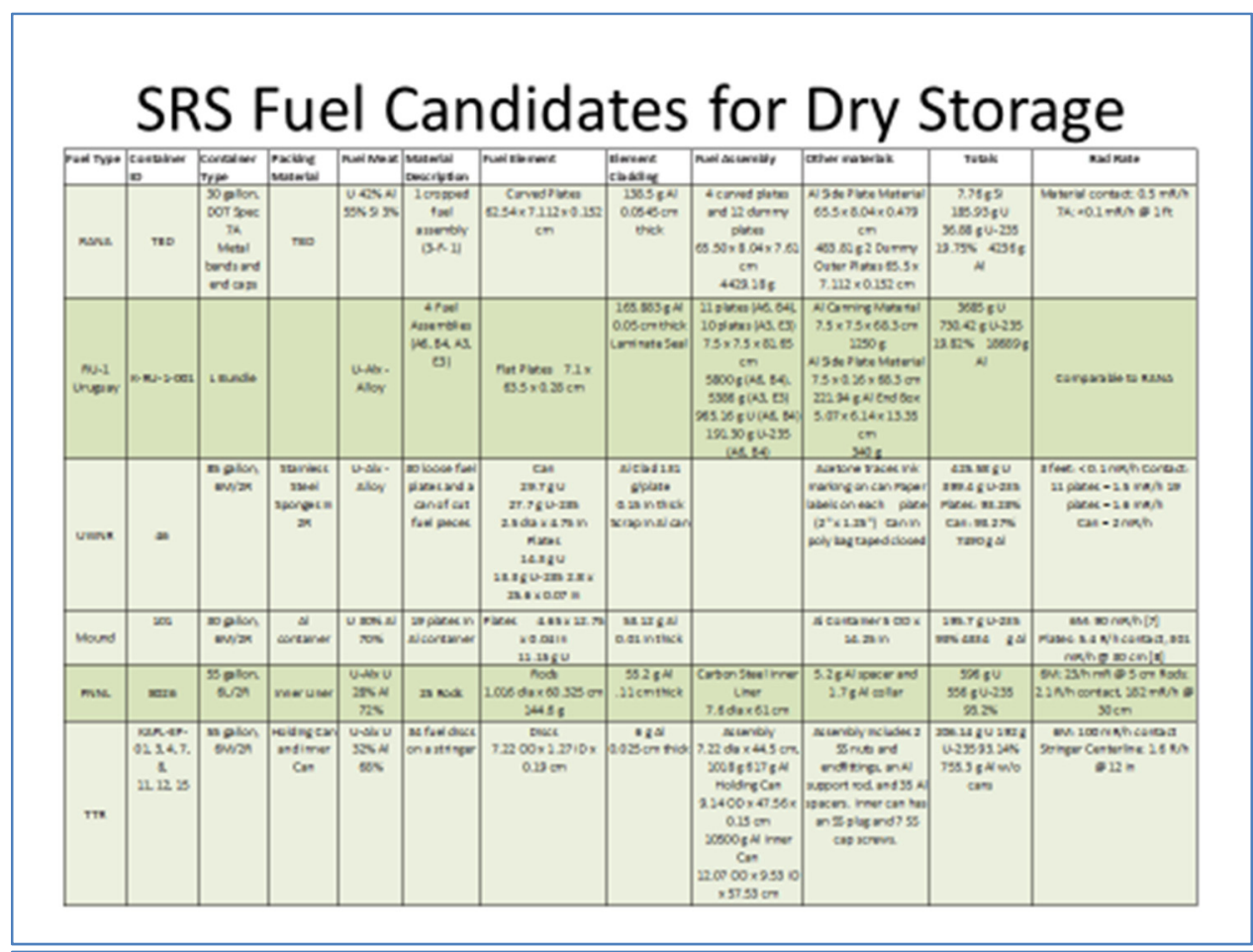

\section{Characterization of Candidate Fuel}

- Characterization of selected ASNF assemblies:

- Formed oxides will be characterized using XRD, XPS, and cross-sectional metallography.

- Fuel physical condition (e.g. extent of damage) will be characterized for distortion from design, area of breach, etc.

- The selected ASNF assemblies will be based on

- fuel design,

- burn-up,

- time in reactor,

- time of wet storage and storage conditions,

- drying conditions,

- dry storage conditions, handling

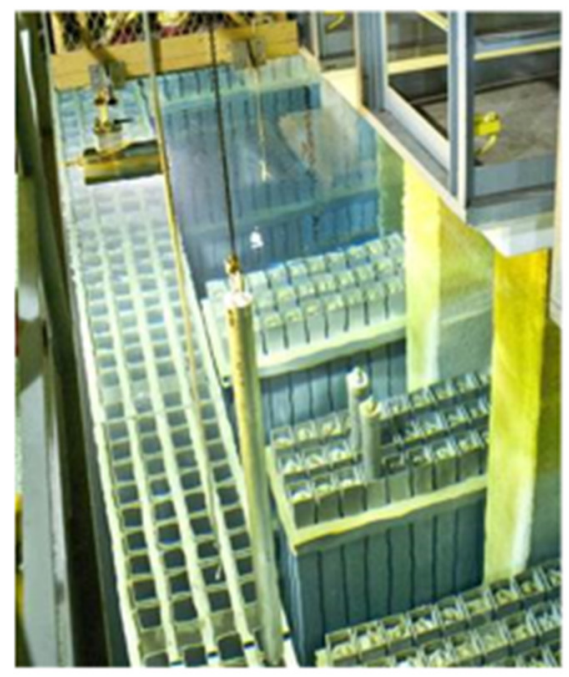




\section{Existing Dry Storage for Research Reactor Fuel--CPP-603 IFSF}

- Commissioned 1974, designed to store Ft. St. Vrain HTGR fuel

- 636 canister positions

- 18 " diameter x $11^{\prime}$ long

- Canisters suspended in steel framework

- Cooling air flows through framework

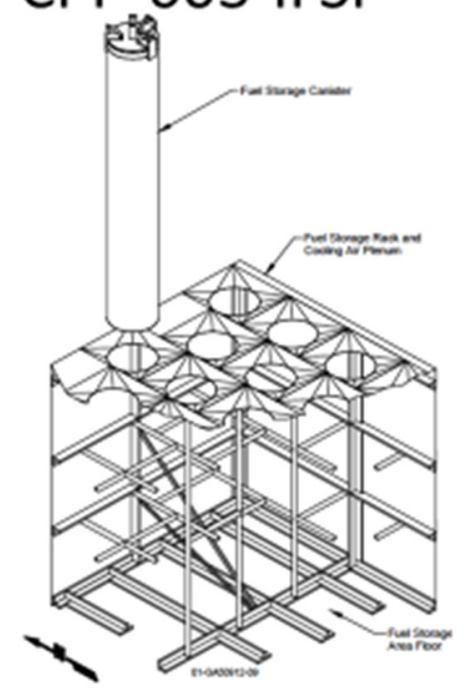

\section{CPP-603 IFSF Dry Storage Operations}

LOAD BUCKETS UNDERWATER

TRANSFER BUCKETS TO DRY FUEL HANDLING CAVE

LOAD BUCKETS INTO CANISTER IN DRYING STATION

HEATED VACUUM DRY

PUT BUCKETS INTO STORAGE CANISTER

TRANSFER STORAGE CANISTER TO STORAGE

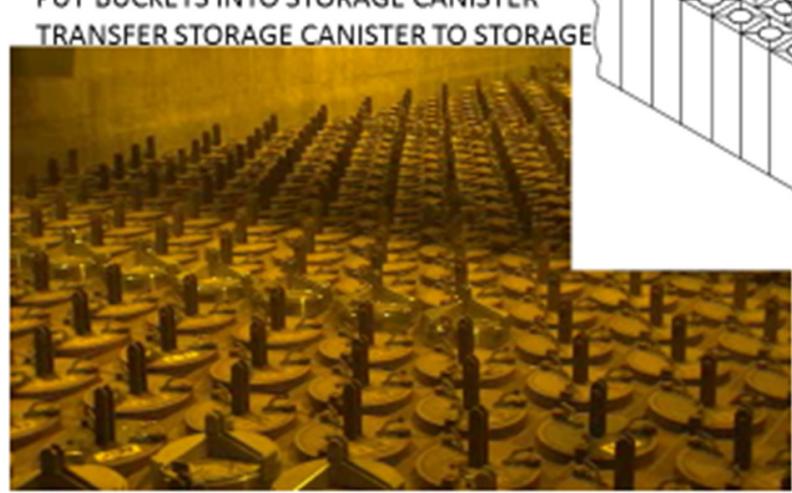




\section{IFSF Storage Canister}

- CAN-GSF-276 Storage Canister

- Nominal Contents 3 buckets, 2 ATR, 1 HFBR, MURR, MTR

- Lid-to-body interface is metal to metal, no O-ring or gasket
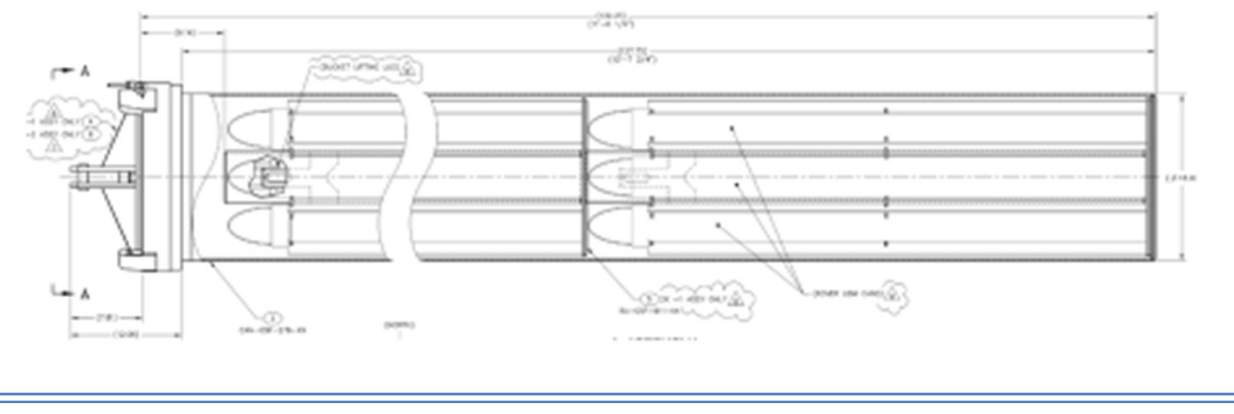

\section{FUEL BUCKET}

- HFBR Shown 28" high

-6 element positions

- ATR Bucket 50" high

-6 and 8 position in service

- Constructed of 304L SS

- Not used in wet storage, only transfer and dry storage

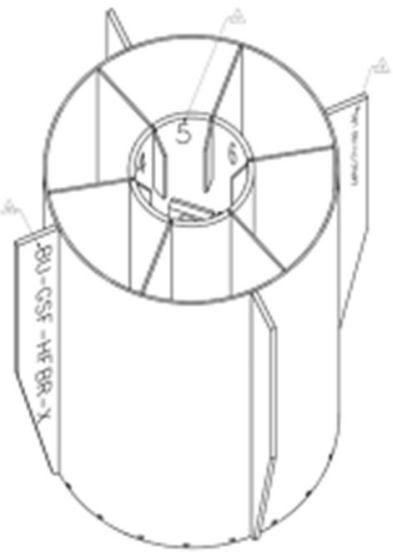




\section{Wet Stored Al Fuel Moved to Dry}

- Stored in cans in water containing minimum 80 ppm chloride

- From Underwater Video Inspection during transfers

- Generally appears intact

- Small white puffs of corrosion

- Assume original oxide displaced at these locations during handling

\section{Wet Stored Fuel Moved to Dry}

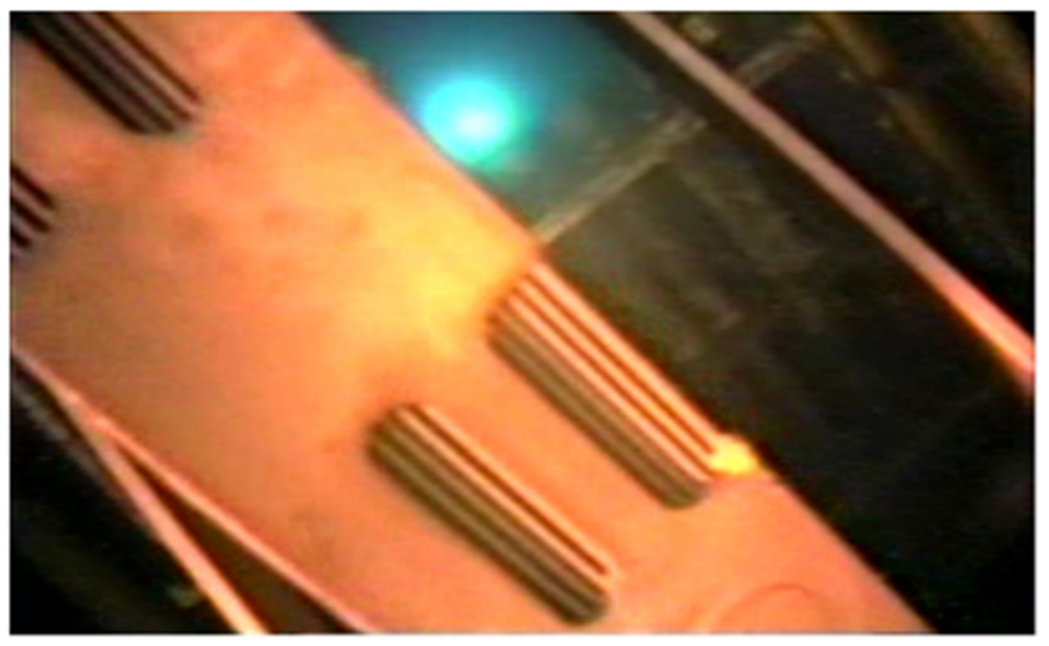




\section{Wet Stored Fuel Moved to Dry}

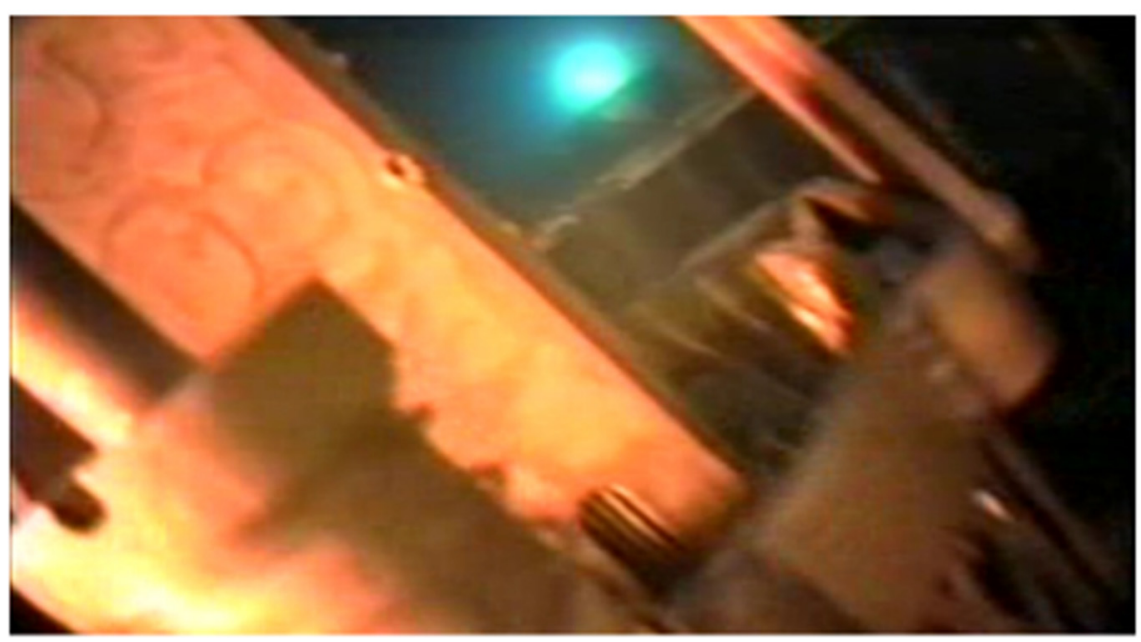

Wet Stored Fuel Moved to Dry

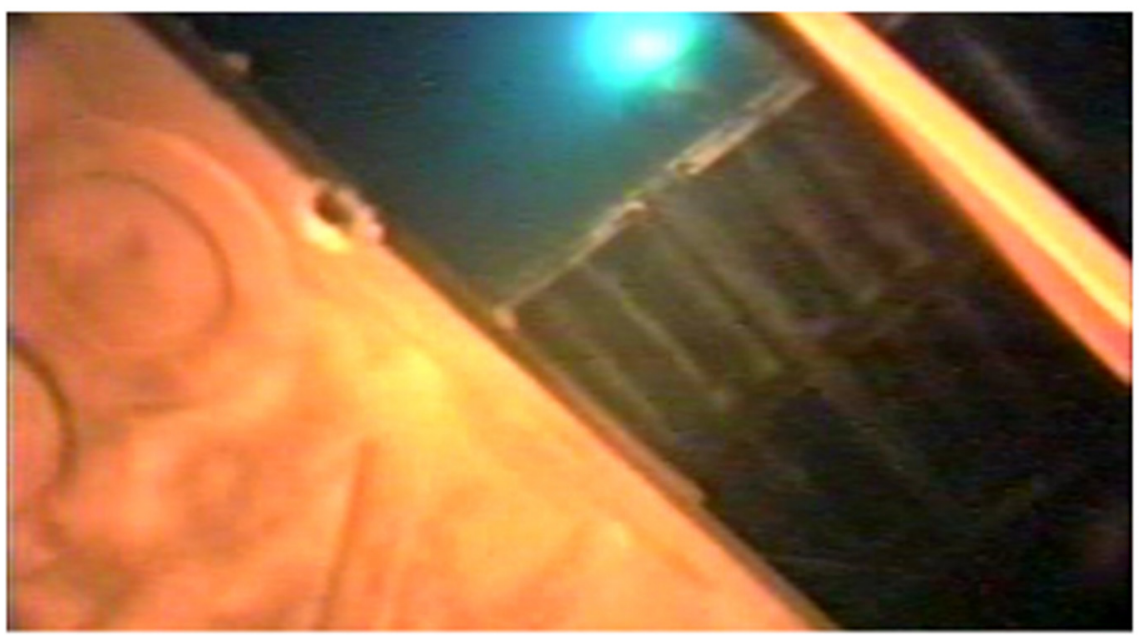




\section{Wet Stored Fuel Moved to Dry}

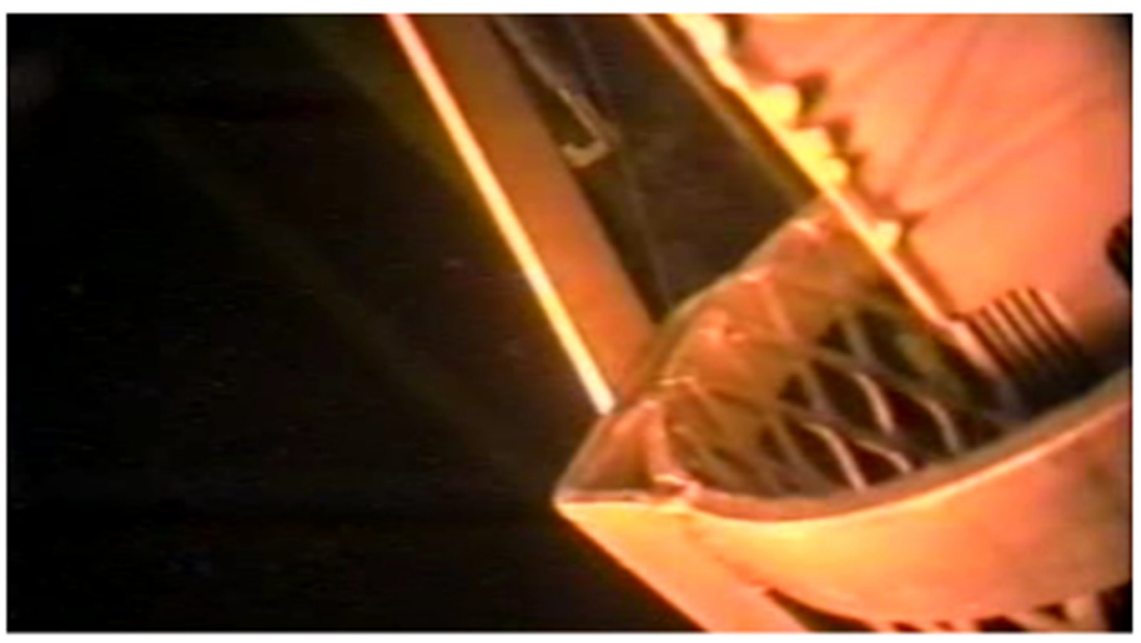

Wet Stored Fuel Moved to Dry

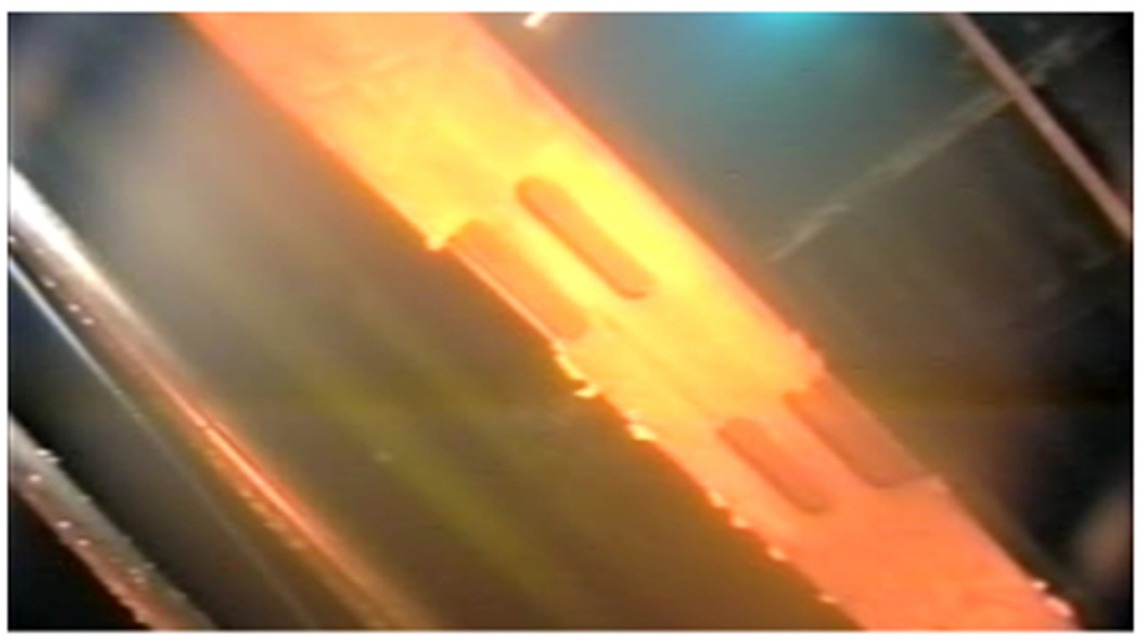




\section{Wet Stored Fuel Moved to Dry}

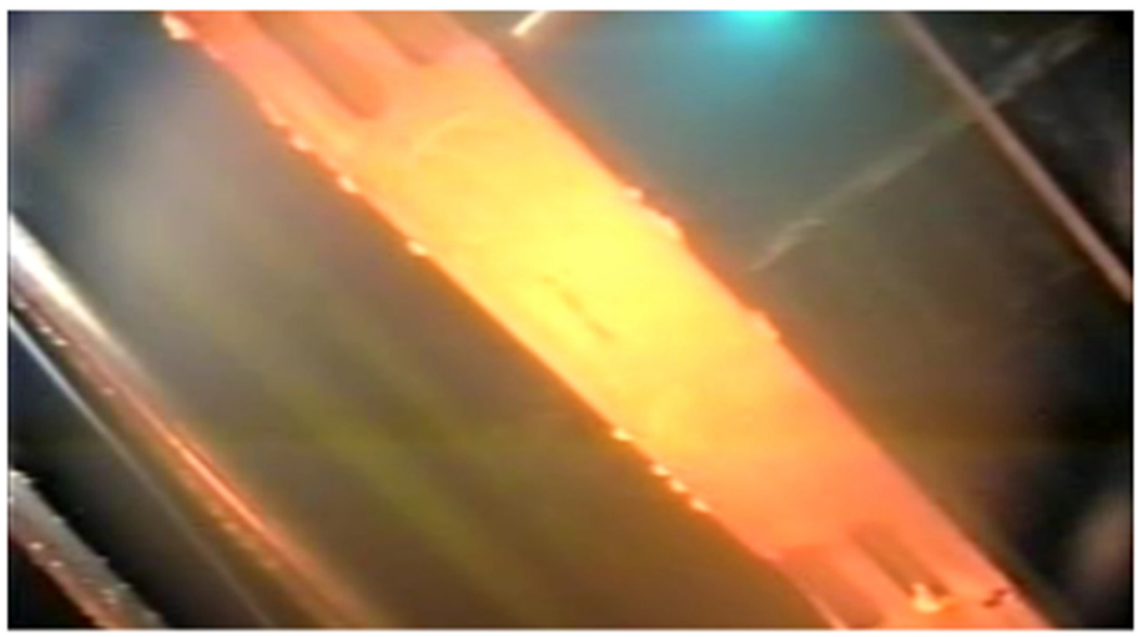

\section{Topic Areas}

- 3. Combined effect of episodic breathing and radiolytic generation of potentially corrosive gases in sealed and vented systems

- Determine if significant seasonal or diurnal temperature changes create a free-standing condensed phase of water

- Determine degree of breathing

- Measure headspace relative humidity

- 4. Performance of research reactor fuel in existing dry storage systems

- Visual exam of exposed surfaces

- Acquisition of representative sample for chemical and phase analysis

- Baseline chemical and phase analysis from end boxes 


\section{Joint Characterization of Items 3 and 4}

- Unless you know the conditions under which the fuel is stored, the data from PIE on oxide layers has limited value

- So-Prior to opening up a canister of stored fuel, careful acquisition of samples of the canister atmosphere will provide data on the prevailing relative humidity, as well as the degree of isolation that the lid provides to resist breathing during pressure and temperature changes

\section{Proposed Approach for Items 3 and 4}

- Construct instrumented $(P, T)$ canister overpack that can be sealed and sampled for headspace composition

- Stage in $24^{\prime \prime}$ cave well in Fuel Handling Cave

- Identify example canisters with:

- Selected burnup

- Known wet storage condition

- Place canister in overpack and backfill with dry argon

- Allow calculated time to elapse for equilibration

- Measure temperature, pressure, radiation field

- Acquire canister headspace sample series to verify equilibration rate

- Optional: Pull a hard vacuum on the overpack to evacuate the canister

- Analyze sample for relative humidity and hydrogen

- Measure temperature and radiation field of canister 


\section{Item 3 Characterization}

- Isolation in insulated overpack with temperature probe

- Measurement of change of overpack fill gas composition with temperature indicates breathing rate through canister lid-body interface

- Measurement of gas sample from complete evacuation of overpack void volume gives indication of total water and hydrogen retained in canister

- Repeat of test after fuel samples (assume return to storage area for $1 \mathrm{yr}$ ) taken would identify variability in headspace composition

\section{Fuel Sample Acquisition}

- Remove canister from overpack

- Remove basket

- Evaluate apparent structural condition for handling

- Visually inspect exposed surfaces of fuel assemblies

- Identify areas where side plate samples could be acquired

- Use minimally-affecting cutting technique to acquire samples (Low speed milling, sawing for low temperature affect)

- Transfer samples to lab for surface oxide thickness and phase characterization

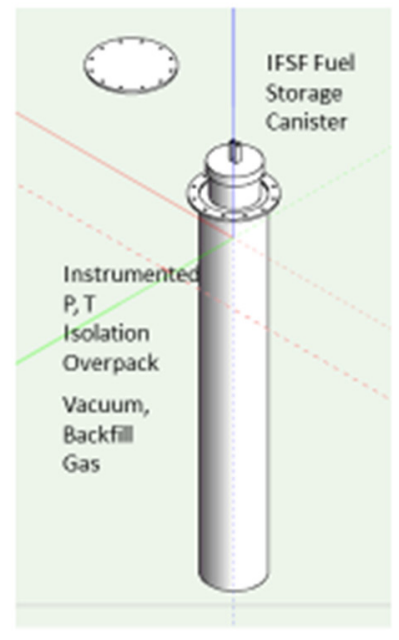




\section{Time and Resource Commitment}

- Headspace Sampling

- Design of Overpack

- 1 structural, 1 mechanical, 1 instrumentation engineer, 1 drafter, checker

- 400 hrs engineering, 80 documentation Total Time 3 months

- Subcontract fab cost $\$ 100,000 ; 6$ month lead time

- IFSF Safety Basis Update

- 1 Safety analyst 200 hrs, Reviewers 200 hrs

- 3 month approval cycle, Total Time 6 months

- Deployment 1 facility engineer, 2 operators SO Test, 120 hrs

- Installation: 2 mechanics, 4 RCTs, 2 electricians, 2 operators;

- Total time 2 months

- Implementation

- Procedure Development, 1 writer 40 hrs, Training 20 hrs, Operators 40 hrs 1 month

- Performance, Engineer, 2 operators, 2 month

- Gas sample transfers, 1 month

- Gas analysis 3 months, $\$ 75 k$

- Total Time 2 years

\section{Time and Resource Commitment Fuel Sample Acquisition}

- Design In-Cell Mill

- 1 mechanical, 1 electrical engineer 120 hrs,

- Equipment Purchase $\$ 7500$

- Machinist Mods 160 hrs

- Mockup Testing (4 Operators 120 hrs) Total Time: 3 months

- Deployment

- 2 Operators, 1 Mechanic, 1 Machinist, 1 electrician, 4 RCTs, 120 hrs 1 month

- Testing 2 operators, 1 machinist, 1 engineer 80 hrs Total Time: 2 months

- Sample Acquisition

- 2 operators, 1 machinist 1 engineer 120 hours Total Time: 1 Month

- Sample Transfer

- Sample Characterization: gamma spec 1 Physicist 60 hrs 1 months

- Cask selection: (Assume GE100) 1 Packaging \& Transportation, 2 facilityengineers Total Time 1 Month

- Transportation Plan Confirmation P\&T Review 1 Month

- Handling Procedure: Writer, Operator, Foreman 80 hours, Total Time 1 Month

- Receipt at HFEF/EML 2 technicians 20 hours

- Total time 12 months 


\section{Canister Monitor 2000}
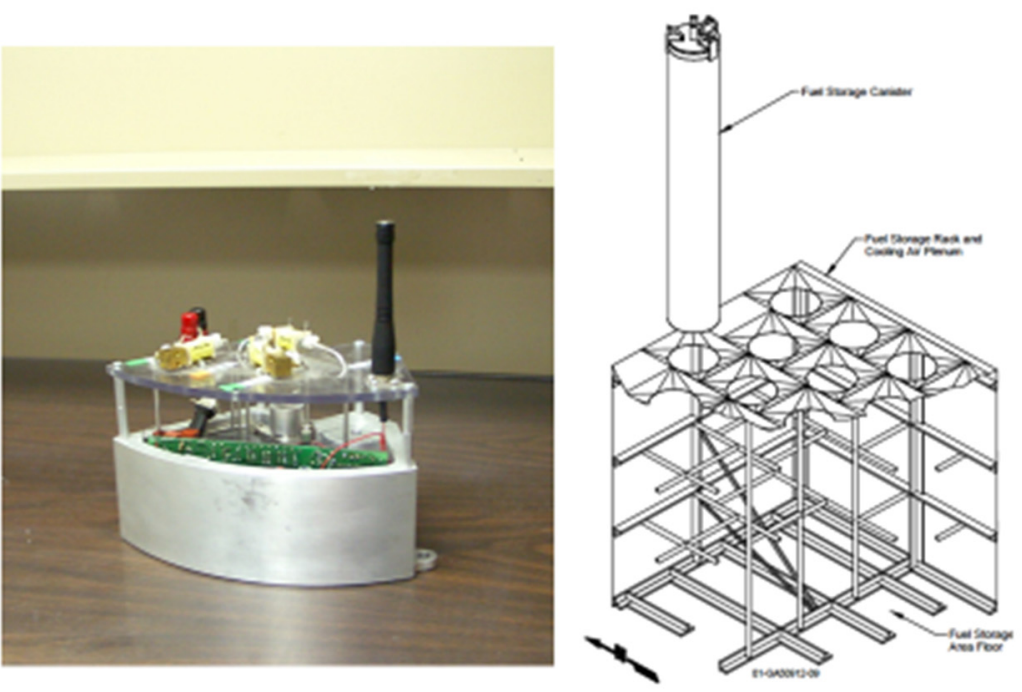

\section{Canister Monitoring}

- Development of a remote wireless instrumentation package for canisters stored in dry Irradiated Fuel Storage Facility (IFSF).

- Measures Relative Humidity, $\mathrm{H}_{2}$, Temperature, Radiation Field (Focus is corrosion and radiolysis)

- Detectors in shielded compartment on canister lid. Penetration in lid to allow gas circulation and direct radiation monitoring

- Prototype to be fielded FY-2000 in Collaboration with University of Idaho.

- Built of as much off-the-shelf commercially-available technology as possible. 


\section{Canister Monitoring}

- Gas sensors: Analog metal oxide conductance/capacitance

- Radiation sensor: Miniature Geiger Mueller tube

- Temperature sensor: Digital -25 to $125 \mathrm{C}$

- Radio Transmitter: $450 \mathrm{MHz}$ Nominal $600 \mathrm{ft}$ range.

- On-board memory: 128K EEPROM (Weekly data for 2 years)--Data retained on-board in the event of battery failure or loss of radio link

- Power source: Lithium batteries. Adaptable to solar cell.

\section{Characterization of Candidate Fuel}

Identification of range of ASNF designs including fuel core material, enrichment, cladding composition, physical design; in-core, and post-discharge storage histories.

tasks 1,2 , and 5

"This inmentory assessment can be used to inform selection of materials and conditions for testing in

Characterization of fuel condition. Advanced PIE should include compositional and dimensional analysis of the cladding and formed oxide/oxyhydroxide layers and structure. Techniques include but are not limited to: cross sectional metallography, XRD, XPS, oxide stability mechanical testing. ultrasonic measurement, BET surface analysis, etc.

Measurements of fuel dimensions (distortions from design) and breach areas using techniques identified above.

Construction of a reference ("bounding") MTR design (based on composite of ATR design, MIT design, etc.) and of a reference degraded MTR fuel conditions; and of a nominal HFIR; and of a nominal pin fuel design, etc. 


\section{Task 5}

"Effects of High Temperature

$\left(>100^{\circ} \mathrm{C}\right.$ ) Drying on the Chemistry and Behavior of

Oxide/Oxyhydroxide Layers"

\section{Task 5 \\ Effects of High Temperature $\left(>100^{\circ} \mathrm{C}\right)$ Drying on the Chemistry and Behavior of Oxide/Oxyhydroxide Layers}

\section{SRNL}

Kallie Metzger

Dennis Vinson

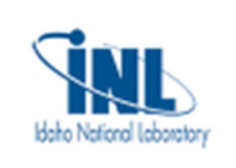

Rebecca Smith 


\section{Problem Statement}

“Optimal conister design and drying operotion becomes importont to ensure effective drying becouse the benefits of the high heot content of commercial SNF is not the case for ASNF.

The drying operation should ensure minimal residual moisture the oxyhydroxide films on ASNF contain chemically bound water thot may result in odditional water vopor dissocioted ot high temperotures and for radiolytic gas generotion under storoge and disposal conditions."

Traasformation sequeaces of transition alemieas

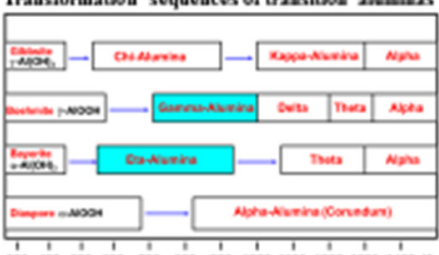

200 400

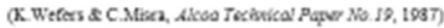

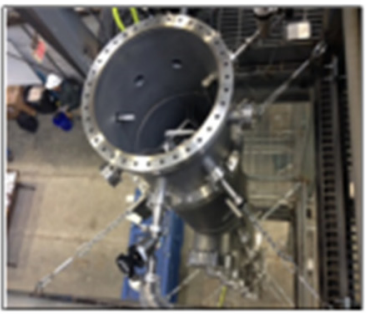

Instrumented drying system

What processes are available to remove chemically bound water in the form of oxyhydroxides to ensure safe extended dry storage?

- Moreover, what are the effects of high temperature drying on the behavior and stability of oxides/oxyhydroxides?

\section{Intended Outcomes}

- Explore thermal treatments for removal of adsorbed water in the form of oxyhydroxides on ASNF.

- Assess thermal stability of oxides/oxyhydroxides as related to drying and extended dry storage (temperature in geologic repository).

- Demonstrate removal process on mini fuel plates using adapted drying technologies.

- Evaluate feasibility of heated canister drying. 


\section{Proposed Work Scope}

1. Evaluate small scale dehydration of oxyhydroxide films:

Oxides/oxyhydroxides grown on Al cladding alloy coupons in task 1 will be subjected to TGA to investigate the stability, decomposition, and transition behavior and kinetics of films.

2. Provide drying demonstration: Test thermal conditions identified in TGA testing to demonstrate drying capabilities for removal of oxyhydroxides.

\section{Evaluate Small-Scale Dehydration of Oxyhydroxide Films}

- Perform thorough literature review to identify documented transition and decomposition temperature ranges which will inform testing procedures and conditions.

- Select applicable Al alloys for testing and document thermal treatments used in alloy fabrication.

*Inquiry regarding relevant current fuel inventory may be supported by efforts in task

4. Task 1 may also provide suitable samples for testing in the form of oxide films on Al substrates.

- Differential thermal analysis (DTA) and Thermal Gravimetric Analysis (TGA) will be used to explore the kinetics and range of thermal decomposition for a diverse and bounding set of laboratory grown oxyhydroxide films and research grade Al oxide powders.

- Results can be used to develop a drying removal procedure for AISNF-to be tested in demo portion of task 5 . 


\section{Provide Scaled-Up Drying Demonstration}

- Plan tests for scaled-up drying using forced gas dehydration technology and/or throttled heated gas vacuum drying technology.

-Thermal analysis results from TGA tests will be used to determine temperatures and conditions required for adsorbed water removal. Scaled-up demonstration will provide necessary proof of concept for observed transition and decomposition behavior.

- Grow oxyhydroxide films on a series of mini plates to develop a collection of diverse samples for scaled-up drying tests.

- Test successful thermal removal procedures previously identified in a series of tests on mini plate specimens with both vacuum and forced circulation drying methods.

\section{Meshing Task 5 Scope With Other Areas}

- Oxides grown on Al cladding alloy coupons in task 1 can be used for dehydration testing (TGA, drying demo) in task 5.

- Task 4 examination and PIE of fuel provides current conditions of oxides in storage. This provides a bounding inventory of oxide/oxyhydroxides.

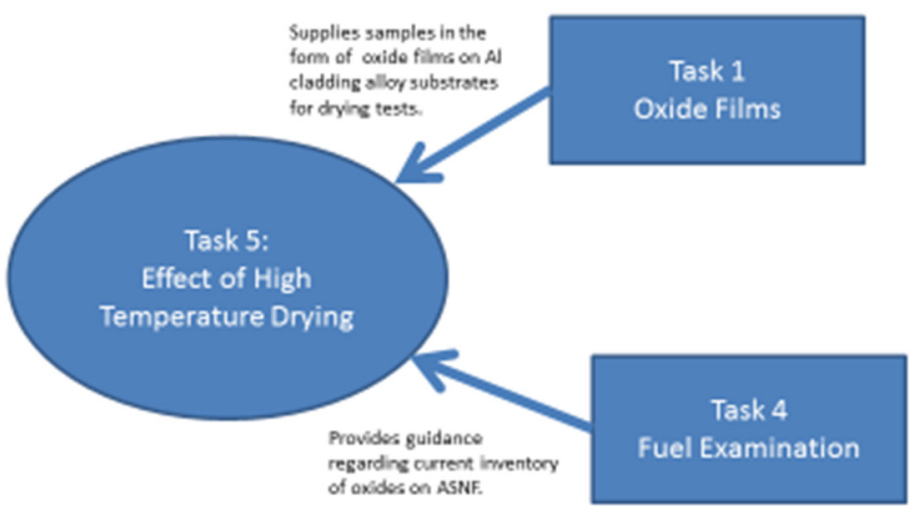




\section{Schedule and Cost of Activities}

\begin{tabular}{|c|c|c|}
\hline Months 0.3 & $\begin{array}{l}\text { Identify Al cladding alloys of interest as well as oxides/oxyhydroxides } \\
\text { films, powiders needed for drying tests. Leverage efforts in task } 1 \text { and } 4 \text {. }\end{array}$ & $30 K$ \\
\hline Months 3-9 & $\begin{array}{l}\text { Subject films grown on substrates to thermal testing in the form of } \\
\text { TGA/DTA. Document decomposition and transition behavior, resolve } \\
\text { kinetics. }\end{array}$ & $200 \mathrm{~K}$ \\
\hline Months 3-12 & $\begin{array}{l}\text { Develop Al cladding alloy mini plates with oxide/oxyhydroxide films for } \\
\text { drying demonstration and testing. }\end{array}$ & $75 K$ \\
\hline Months 1-12 & $\begin{array}{l}\text { Develop a system to perform scaled-up drying demonstration. } \\
\text { "Budget will be relieved if the project modifies an existing } \\
\text { drying focility rother than constructs a new one. }\end{array}$ & $300 \mathrm{~K}$ \\
\hline \multirow[t]{2}{*}{ Months 12-18 } & $\begin{array}{l}\text { Successful thermal removal temperature/time conditions identified } \\
\text { earlier in this task will be tested in a series of drying experiments on mini } \\
\text { fuel plates with vacuum and forced circulation drying methods. }\end{array}$ & $300 \mathrm{~K}$ \\
\hline & Total: 18 months & $\approx 900 \mathrm{~K}$ \\
\hline
\end{tabular}

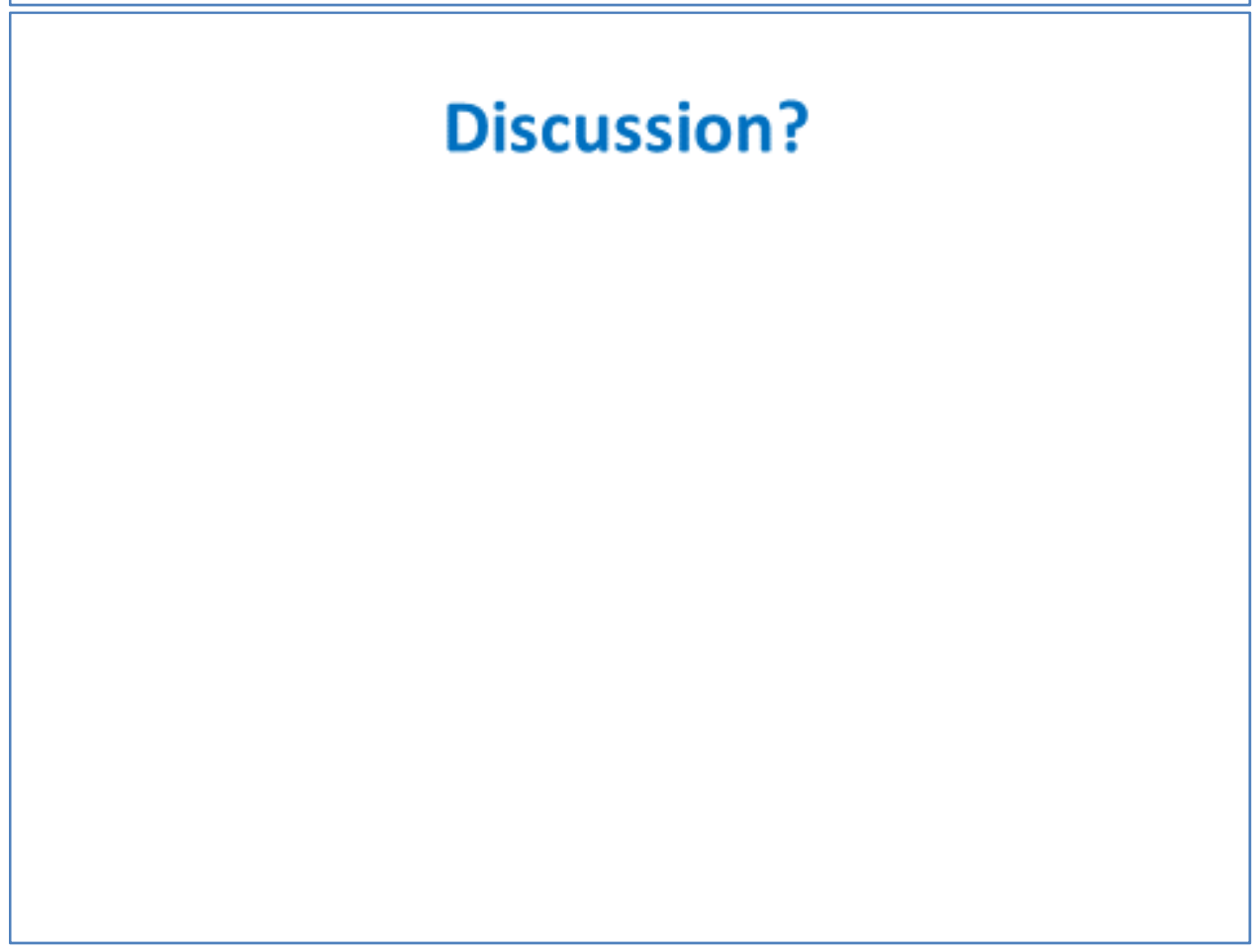




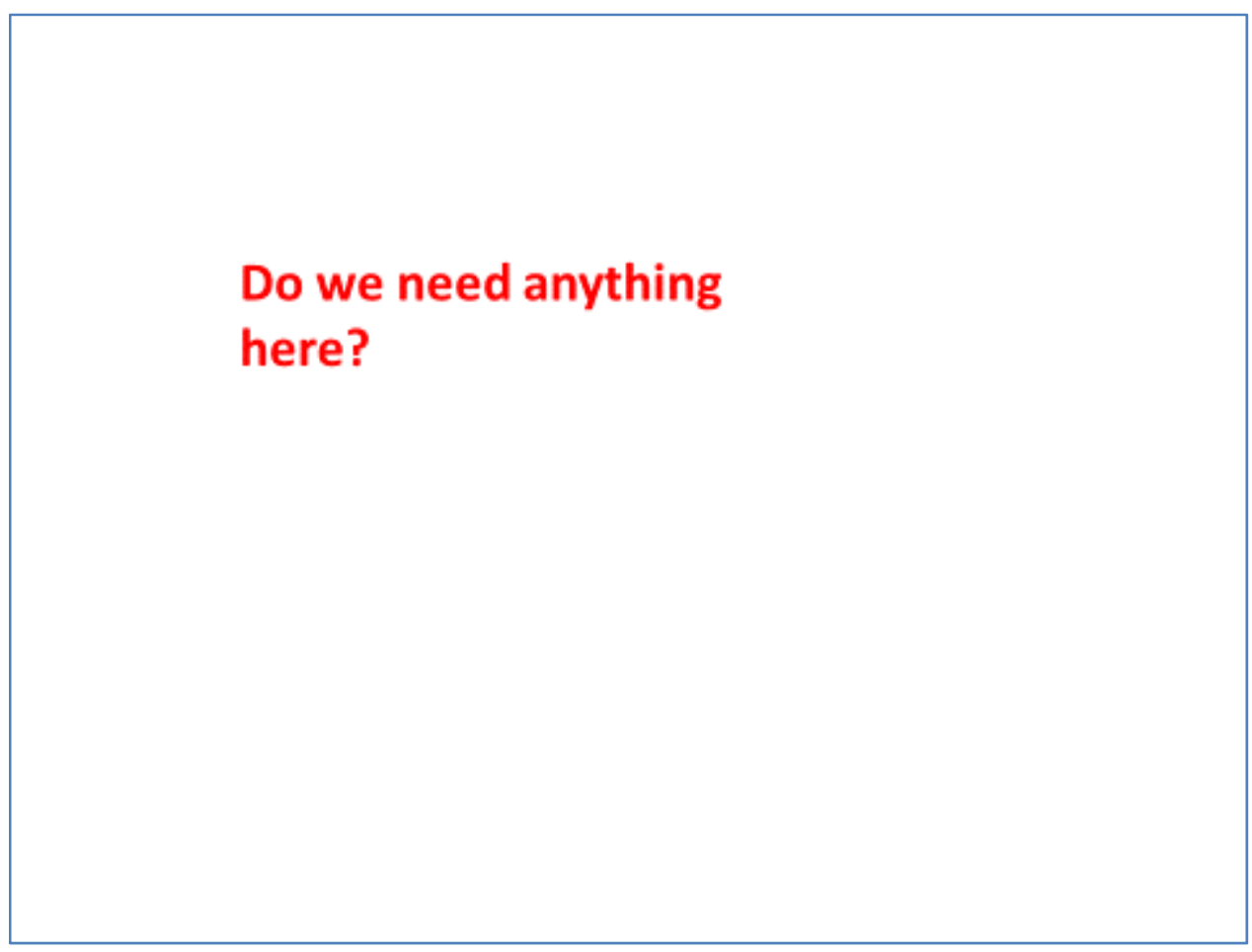

